2014-06-01

\title{
Controls on macrotidal rip current circulation and hazard
}

Scott, Tim

http://hdl.handle.net/10026.1/3095

10.1016/j.geomorph.2014.02.005

GEOMORPHOLOGY

Elsevier BV

All content in PEARL is protected by copyright law. Author manuscripts are made available in accordance with publisher policies. Please cite only the published version using the details provided on the item record or document. In the absence of an open licence (e.g. Creative Commons), permissions for further reuse of content should be sought from the publisher or author. 


\section{CPRG Paper2}

\section{COASTAL PROCESSES WITH \\ Coastal Processes Research Group \\ School of Marine Science and Engineering \\ University of Plymouth \\ Drake Circus \\ PLYMOUTH, PL4 8AA \\ United Kingdom}

Contact:

daniel.conley@plymouth.ac.uk

The Coastal Processes Research Group is an internationally recognised group of researchers, specialising in field studies of coastal processes. We aim to be a leading contributor to the international research community seeking to understand and predict the behaviour of coastal and estuarine systems in support of appropriate management of coastal resources and activities.

\section{Example Research Areas}

- beach morphodynamics and nearshore sediment transport

- coastal erosion and storm impacts

- video monitoring of coastal systems

- coastal process modelling

- $\quad$ estuarine processes and evolution

\section{Paper details}

\begin{tabular}{|c|c|}
\hline Citation & $\begin{array}{l}\text { Scott, T., Masselink, G., Austin, M. J. Russell, P. 2014. Controls on macrotidal rip current circulation } \\
\text { and hazard, Geomorphology, 214, 198-215. ISSN 0169-555X, } \\
\text { http://dx.doi.org/10.1016/j.geomorph.2014.02.005. }\end{array}$ \\
\hline Author(s) & Tim Scott, Gerd Masselink, Martin J. Austin, Paul Russell \\
\hline Corresponding Author & Tim Scott: timothy.scott@plymouth.ac.uk \\
\hline Funding bodies & RNLI/NERC \\
\hline Paper URL publisher & http://dx.doi.org/10.1016/j.geomorph.2014.02.005 \\
\hline Date submitted & 8 August 2013 \\
\hline
\end{tabular}




\title{
Controls on macrotidal rip current circulation and hazard
}

\author{
Tim Scott ${ }^{\mathrm{a}, *}$, Gerd Masselink ${ }^{\mathrm{a}}$, Martin J. Austin ${ }^{\mathrm{b}, * *}$, Paul Russell ${ }^{\mathrm{a}}$ \\ ${ }^{a}$ School of Marine Science and Engineering, University of Plymouth, Drake Circus, Plymouth, PL4 8AA, UK \\ ${ }^{b}$ School of Ocean Sciences, Bangor University, Menai Bridge, Anglesey LL59 5AB, UK
}

\begin{abstract}
Rip currents are strong, narrow seaward-flowing currents in the surf zone and are common on energetic sandy beaches. They are generally associated with distinct beach morphology, comprising nearshore sand bars and channels, and represent a real natural hazard to surf zone users. Rip current circulation is primarily driven by spatial gradients in wave breaking and water levels in the surf zone, which in turn are controlled by beach morphology, offshore wave conditions and tidal level. These factors, which are highly variable over hours (tides), days (waves) and weeks (morphology), also control the rip risk to bathers. However, the precise roles of these different environmental factors in controlling rip dynamics on meso- to macro-tidal beaches is not exactly known and thresholds separating different types of rip circulation and flow strengths, and hence rip risk, have not been quantified. Here, analysis of 5-year lifeguard incident records from 20 beaches in southwest England showed that high-risk, high-exposure scenarios for bathers occur disproportionately around mean low water on days with low wave height $\left(H_{s}<1 \mathrm{~m}\right)$, long wave period $\left(T_{p}>10 \mathrm{~s}\right)$, shore-normal wave approach and light winds $\left(>5 \mathrm{~m} \mathrm{~s}^{-1}\right)$. Detailed in-situ Lagrangian field measurements of rip currents collected on 23 different days from Perranporth Beach, UK identified waves (characterised by $H_{s} T_{p}$ ) and active morphology (characterised by tidal elevation) as the key controlling factors determining the mode of rip behaviour. Maximum hazard was associated with the combination of maximum rip exits and rip flow speeds. These conditions occurred when $H_{s} T_{p}$ was at or just below average values and when those waves were acting on the active morphological template, around mean low water. The thresholds in wave conditions and tidal elevation identified here were effective in discriminating between observed coast-wide high-risk incident events, illustrating that such mass rescue events have a considerable element of environmental control. Because many beaches along the west coast of southwest England are characterised by nearshore bar morphology just below the mean low water level, and are affected by similar wave and tide conditions, the results obtained from this beach are transferable to other locations. The findings of this study may also have implications for other beaches with nearshore bar-rip morphology at specific tidal levels.
\end{abstract}

Keywords:

rip currents; beach morphodynamics; beach morphology; macrotidal; beach hazard; beach safety.

\section{Introduction}

Rip currents are ubiquitous features in energetic surf zones. They can occur on many types of beaches under a variety of wave conditions and tidal levels. A concerted research effort over recent years, significantly aided by technological advances in field instrumentation and computer modelling, has dramatically improved our quantitative understanding of these wave-driven offshore-directed surf zone currents (Brander, 1999; MacMahan et al., 2004; Reniers et al., 2004; MacMahan et al., 2005; Brander and Short, 2006; Reniers et al., 2006; Bruneau et al., 2009; Austin et al., 2010; MacMahan et al., 2010; Reniers et al., 2010; Bruneau et al., 2011; Austin et al., 2013). Rip currents are generated by alongshore variations in breaking

\footnotetext{
*Corresponding author

** Previously at: School of Marine Science and Engineering, Plymouth University, Drake Circus, Plymouth PL4 8AA, UK

Email address: timothy.scott@plymouth.ac.uk (Tim Scott)
}

wave heights (Bowen, 1969). Nearshore bathymetric variations on open-coast beaches, due to evolving sandbars and troughs, drive alongshore variation in depth-induced breaking. The resulting 'open-coast beach rip currents' are the most common type globally (MacMahan et al., 2011). The occurrence, scale, strength and behaviour of these rip currents are determined by nearshore and coastal morphology, wave characteristics (height, period and direction), tidal water level and wind (Dalrymple et al., 2011). Rip currents can also occur near rocky outcrops and coastal structures as well as headland-embayed beaches. These rip types are often referred to as topographic and mega rip currents and their behaviour can vary significantly from open-coast beach rips. This paper focuses on open-coast beach rip currents driven by wave breaking over nearshore sandbar morphology.

Open-coast beaches not influenced by coastal structures or headlands display a wide variety of rip current shapes that are controlled by the beach morphology. The 
presence of rip currents is most commonly associated with intermediate-type beach morphology (Wright and Short, 1984). The active sandbar morphology often forms semirhythmic, shallow shore-connected shoals, incised by deeper rip channels. This longshore non-uniformity is important in determining the flow kinematics of a rip system (Brander and Short, 2001; MacMahan et al., 2006).

Until recently, rip current research has focussed on micro- and mesotidal environments (e.g. Shepard et al., 1941; McKenzie, 1958; Bowen and Inman, 1969; Huntley et al., 1988). Recent studies along the west coasts of France and UK, where mean spring tide ranges (MSR) are $3-8 \mathrm{~m}$, have highlighted the important tidal control on rip current dynamics in macrotidal tidal regions (Castelle et al., 2006; Bruneau et al., 2009; Austin et al., 2010; Scott et al., 2011a).

Rip currents are known to be modulated by tidal level, with decreases in water surface elevation increasing rip current flows to a relative maximum (e.g. Aagaard et al., 1997; Brander, 1999; Brander and Short, 2001; MacMahan et al., 2005, 2006). This modulation has been linked to temporal changes in the expression of the morphological template causing: (1) spatial and temporal variation in the pattern of wave dissipation; and (2) morphological flow constriction (Austin et al., 2010). Brander (1999) presents a conceptual model from a microtidal beach whereby the morphodynamic behaviour of rip currents is placed within the context of the Wright and Short (1984) beach state model. Specifically, down-state accretionary transitions are linked to a decrease in the cross-sectional area of the rip channel and lead to the development of a rip head bar, which constricts flows and modifies the wave dissipation pattern. Field studies by Austin et al. (2010) at Perranporth, UK, a macrotidal $(\mathrm{MSR}=6.3 \mathrm{~m})$ low-tide bar $/ \mathrm{rip}$ (LTBR) beach, show a similar modification of rip flows, but due to tidal modulation of water levels at semi-diurnal frequencies rather than beach morphological evolution.

Temporal modulation of rip circulation induced by the falling tide level observed by Austin et al. (2010) was considered akin to inner bar state transitions through the rhythmic bar-beach (RBB), RBB-transverse bar/rip (TBR) and TBR-low-tide terrace (LTT) states; as the tide fell, bar relief was maximised, increasing flow channelisation on the inner bar and wave breaking on the outer bar, leading to the modification of rip circulation patterns and behaviour at the semi-diurnal timescale. Further modulation occurs at the spring-neap timescale due to the variation in tidal range from 6 to $3 \mathrm{~m}$, respectively.

Recent field (MacMahan et al., 2008; Austin et al., 2013) and laboratory (Castelle et al., 2010) studies have shown that on both the micro/mesotidal TBR beaches and the meso-macrotidal low-tide bar/rip (LTBR) and low-tide terrace and rip (LTTR) beaches (Masselink and Short, 1993; Castelle et al., 2007; Scott et al., 2011a), rip current circulations commonly form eddy-like cells, largely constrained within the surf zone, with occasional pulses beyond the surf zone, also referred to as 'exits'.
Using GPS-tracked surf zone drifters to measure these rip current circulations, recent studies found that in moderateenergy, micro/mesotidal settings the rip circulation retained the majority of drifters within the surf zone with only $19 \%$ (range: $4-28 \%$ ) of exits. Similar experiments in France and the UK in moderate-energy, meso/macrotidal and double-barred environments found average drifter exits per hour to be $14 \%$ and $16 \%$, respectively, but with ranges of 0 to $34 \%$ (MacMahan et al., 2010). Reniers et al. (2009) defined an exit parameter $(E)$ based on extensive modelling and field measurements of rip current circulations on single barred beaches, where:

$$
E=\frac{X_{w}}{H_{r m s, 0} T_{m 01}}
$$

where $X_{w}$ is the surf zone width, $H_{r m s, 0}$ is the rootmean-squared wave height at the offshore boundary and $T_{m 01}$ is the mean wave period. Their results indicated that it is important to account for both Stokes drift and very low frequency motions (VLFs), typically $O(10 \mathrm{~min})$ time scales, to achieve modelled exit statistics similar to those observed on a microtidal beach.

Through the analysis of multiple surf zone drifter datasets over the full range of tidal regimes MacMahan et al. (2010) suggests a morphodynamic threshold may exist for crossshore exchange by rip currents where larger waves (breaking further offshore) induce coherent vortices on the order of surf zone dimensions and which retain material within the surf zone, thus reducing surf zone 'exits'. For lower wave heights, decreased morphodynamic coupling encourages cross- and alongshore exchange, resulting in an increase in surf zone 'exits' until the flow field becomes much less energetic and weak alongshore currents dominate. High-energy, meso- to macrotidal sandy beaches can have multiple bar systems, and Castelle et al. (2007) highlighted the importance of the intermittent morphodynamic coupling between outer and inner bars in controlling rip currents.

The dynamic relationship between morphology and rip current circulation has significant relevance for beach safety. Rip currents can quickly move swimmers spatially to regions of deeper water and/or greater hazard, and have globally been documented as a significant natural hazard (Shepard, 1949; Short and Hogan, 1994; Short, 1999). Recent investigations of beach hazards in the UK, Australia and the United States indicate that rip currents represent the single most significant cause of rescues and fatalities for beach users (Short and Brander, 1999; Scott et al., 2007, 2008, 2011a; MacMahan et al., 2011; Brighton et al., 2013). Specifically, Scott et al. (2008) noted that $68 \%$ of all incidents recorded by the Royal National Lifeboat Institution (RNLI) on UK beaches were due to rips. Furthermore, over $90 \%$ of recorded UK rip incidents were shown to occur on beaches with identifiable rip channel morphologies (i.e., LTBR and LTTR). The macrotidal beaches that dominate the UK coast introduce unique tide-related complexities into understanding beach hazards. 
Beach hazards, like morphodynamics, vary temporally. Fig 1 presents a conceptual rip current hazard framework, termed the 'Temporal Hazard Signature' (THS), which describes the key controls on rip hazards in the UK over a range of time scales. (1) Annual long-term characteristic beach types, controlled by environmental setting, are linked with varying rip current activity. High energy beach types with dynamic sandbar systems (LTTR and LTBR in the UK) are associated with the highest rip hazard in the UK. (2) Seasonal changes in the wave climate, and in turn sand bar morphology, drive associated changes in rip current activity and hazard. (3) Weekly variations in rip activity are controlled by lunar (spring/neap) tidal modulation through vertical water level excursion and wave events. Finally, (4) prevailing rip dynamics and hazards can vary dramatically from hours to seconds controlled by variability in water level, wave conditions and wind. [FIGURE 1]

Previous rip current hazard research described in Scott et al. (2011b) indicates that there are certain combinations of environmental controls, which are conducive to causing rip-related mass rescue events. In particular, the combination of well-developed low-tide bar/rip morphology, the onset of small-to-medium long-period swell waves and larger tides were observed to be a key factor in driving periods of high rip current risk. This study aims to quantify the dynamics of rip currents within these environments throughout a range of conditions, enabling the identification of the forcing conditions and rip dynamics controlling bathing hazards and high-risk scenarios. This paper will address these aims through a combination of in-depth analysis of rip current incident statistics, field measurements and numerical modelling.

\section{Regional setting}

\subsection{Study region}

The datasets presented in this paper were collected along the high-relief, mainly rocky west coasts of Devon and Cornwall in the southwest of England (Fig 2). The Atlantic southwest coast of England represents a macroto megatidal high-energy exposed environment dominated by high hard-rock cliffs, open and embayed sandy beaches. This coast receives a mixture of Atlantic swell and locallygenerated wind waves and represents the most energetic wave climate in England. It provides a unique site for investigating the role of rip currents and beach hazards on high-energy sandy beaches with large tidal ranges. These beach environments present the greatest risk to bathers in the United Kingdom (Scott et al., 2011b).

Seasonal variations in wave conditions in the southwest of England are notable and mean offshore significant wave heights $\left(H_{s}\right)$ at Seven Stones Light Vessel (506'9" $\mathrm{N}, 6^{\circ} 60^{\prime \prime} \mathrm{W}$ ), off the southwestern tip of Cornwall, varied from $2.4 \mathrm{~m}$ in winter to $1.2 \mathrm{~m}$ during summer over the period 2003-2008. The $10 \%$ exceedance wave heights
$\left(H_{10}\right)$ during winter and summer were $4.8 \mathrm{~m}$ and $2.2 \mathrm{~m}$, respectively. Analysis of the joint wave distributions indicates that a significant portion of the increase in energy during the winter months is due to storms with relatively long-period waves (mean wave period $T_{m}$ up to $14 \mathrm{sec}$ ).

To investigate the physical controls on rip current hazard, twenty beaches were selected for the analysis of rip current hazards (Fig 2). All the sites have similar low-tide bar/rip beach morphology (LTBR and LTT + R) and were considered to be open-coast (not embayment-dominated) dominated by beach rip systems that were not constrained by geology. Lower beach grain size distributions are well sorted for all beaches and median grain sizes $\left(D_{50}\right)$ range from 0.29 to $0.45 \mathrm{~mm}$. The rip current incidents recorded at these sites between 2006 and 2010 were coupled with model hindcast environmental forcing (waves, tide and wind) to investigate environmental controls on rip hazard. All sites are popular tourist and surfing beaches and had a RNLI lifeguard service between 2006 and 2010 with a complete incident record throughout the study period. Rip current incidents are recorded by the duty beach lifeguard and represent a situation where a lifeguard is required to take action to assist or rescue a water user from a rip current. [FIGURE 2]

Previous field studies by Scott et al. (2008) document significant seasonal variation in beach volume and morphology across six of the twenty beaches. Typically, lowenergy accretionary conditions with well-developed lowtide transverse bar/rip systems, present throughout all beaches, are modified through high-volume offshore sediment transport during prolonged high-energy winter storm events, causing seasonal intertidal beach lowering of up to $0.5 \mathrm{~m}$ along the studied beaches. The study also provided evidence of the synchronous behaviour of open-coast morphological evolution of nearshore sandbar systems within the west coast region between July 2006 and February 2008, where measurements of intertidal beach volume changes and monthly digital images of bar formations followed a similar evolutionary pattern throughout the study period.

To fully understand the connection between rip incidents on LTBR beaches and the physical dynamics of rip current hazard, field measurements of rip currents were collected at Perranporth beach in Cornwall during two field campaigns in 2011 (May-June and October) (Fig 3). Perranporth is a macrotidal beach with a semi-diurnal tidal regime and a mean spring range of $6.3 \mathrm{~m}$. It is a LTBR beach type and, similar to other beaches in the region, exhibits pronounced low tide bar/rip morphology which varies on a seasonal timescale. The intertidal beach is relatively flat $(\tan \beta=0.015-0.025)$ and composed of medium quartz sand $\left(D_{50}=0.28-0.34 \mathrm{~mm}\right)$. The beach faces west-northwest and is predominantly exposed to Atlantic swell, but also receives locally generated wind waves; it has an annual average significant wave height and peak period of $H_{s}=1.5 \mathrm{~m}$ and $T_{p}=10.6 \mathrm{~s}$, respectively. Perranporth is regarded as a representative example of both the typical nearshore bar/rip morphology that exits along 
the exposed coasts of Devon and Cornwall, as well as on high-energy macrotidal beaches globally.

Fig 3 illustrates the beachface morphology at Perranporth during one of the field experiments and shows the presence of an extensive transverse bar system with incised rip channels located just below the mean low water neap (MLWN) elevation. The sub-tidal bar is located approximately $200 \mathrm{~m}$ seaward of mean low water (MLW). The incised channels in the inner bar were quasi-periodic with a spacing $O(200-500) \mathrm{m}$ and were intermittently welded to the outer bar. Analysis of 3103 video images from Perranporth between 2006 and 2012 provided comprehensive baseline measurements of the long-term rip channel geometry. The low tide pixel intensity image clearly identifies the extent of the surf zone and indicates that waves are breaking on the seaward slope of the transverse bars. Mean alongshore rip spacing was $363.5 \mathrm{~m}(\sigma=108 \mathrm{~m})$, mean rip channel width was $27.5 \mathrm{~m}(\sigma=8.6 \mathrm{~m})$ and mean rip channel angle to shore-normal was $22.9^{\circ}\left(\sigma=12.4^{\circ}\right)$ with $97 \%$ of the rip channels orientated to the south (Prodger, 2012). Research by Short and Brander (1999) using data from Europe, the United States, Japan, South Africa and New Zealand found that average beach rip spacing was 500 $\mathrm{m}$ for west coast swell settings. [FIGURE 3]

\section{Data collection}

Two main datasets are analysed in this study: (1) a long-term record of inferred rip hazard through RNLI lifeguard incident records over the period 2006-2010, coupled with hindcast modelled waves, wind and tidal levels, supported by video imagery and a series of nearshore bathymetries for Perranporth over the period 2010-2012; and (2) two short-term intensive field experiments at Perranporth beach during 2011 which compiled a dataset of Lagrangian rip current measurements using GPS-tracked surf zone drifters, forcing hydrodynamics, bathymetry and Argus video imagery.

\subsection{Long term dataset}

Rip current-related lifeguard incidents give an indication of levels of rip current hazard at a given location. It is also important to consider the exposure to the hazard through the number of people in the surf zone as it will have a significant effect on the incident count.

The incident records presented here are from the seasonal RNLI lifeguard service that runs between March and October at the twenty selected sites (Fig 4). All RNLI lifeguard units record details of every incident occurring at their beach, including information on the environmental causes of incident (e.g., rip currents), as well as the number of people involved in each incident. For the purpose of this analysis, an incident is expanded to always represent an individual. So an incident involving two bathers would, for the purpose of this study, be represented as two incidents. Daily logs of beach and environmental conditions are also collected. These include visual estimates of numbers of people on the beach and in the sea every hour during patrol. These records provide a qualitative dataset of human surf zone exposure. This RNLI dataset is, to our knowledge, the only detailed comprehensive and consistent record of rip risk levels (incidents and beach population) over an extended period of time at multiple locations.

In order to investigate the role of environmental forcing of rip current hazard, 3-hourly (zero-hour) hindcast wave and wind model data were coupled to each individual incident record over the period 2006-2010. Key parameters, including significant wave height $H_{s}$, peak wave period $T_{p}$, mean wave direction from total wave spectrum in degrees $D_{m}$, mean wind speed $W_{s m}$, and mean wind direction $W_{d i r}$, were derived from the MetOffice European 8-km WaveWatch III wave model (Tolman and Chalikov, 1996). Model outputs were taken from four nodes located as close as possible to key beach clusters along the studied section of coast (Fig 2). Tidal elevation data were also obtained through harmonic analysis of previous data from the field site.

The nearshore bathymetry was surveyed at Perranporth beach at 6-weekly intervals (2010-2012). Intertidal beach elevation surveys used a survey grade RTK-GPS mounted on an all-terrain vehicle (ATV) to measure from the dune system to mean low water springs (MLWS). Subtidal bathymetric surveys used an RTK-GPS and singlebeam echo-sounder mounted on a personal water craft (PWC) to measure bed level to a depth of c.16 m. Data were processed using a scale-controlled, quadratic loess interpolator, which allowed control of smoothing levels and reduction of sampling errors (Plant et al., 2002). Data were interpolated onto a regular grid and transformed into a local coordinate system $[\mathrm{X}, \mathrm{Y}]$, where $\mathrm{X}$ is directed crossshore and increases to seaward and $\mathrm{Y}$ is alongshore increasing to the south (Fig 3). Bathymetric data were collected along regularly-spaced cross-shore transects $(\Delta \mathrm{Y}=$ $25 \mathrm{~m}$ ), which overlapped with the intertidal survey by approximately $100 \mathrm{~m}$. Higher frequency (weekly) nearshore surveys were conducted during field experiments.

A cliff-mounted Argus video system overlooking the southern part of the beach at Perranporth provided information on wave breaking over the nearshore morphology (Holman and Stanley, 2007). Time-averaged images, recorded every $30-\mathrm{min}$, covered the bar/rip region and were merged and rectified onto the same local coordinate system as the bathymetric measurements. High-resolution images have been collected continuously since 2006 .

\subsection{Short term dataset}

A directional wave rider (DWR) buoy located c. 1.2 $\mathrm{km}$ offshore in 13-m water depth provided offshore wave measurements throughout the field experiment. As with the long-term analysis, tidal elevation data during deployments were predicted through harmonic analysis of previously collected data.

The surf zone circulation associated with rip current flows was measured using GPS-tracked drifters. In total, 
drifters were deployed in the surf zone at Perranporth for 25 days during 2011, providing a dataset of $40 \mathrm{ebb}$ or flood tide sequences and c. 100 hours of Lagrangian data. Each day consisted of the simultaneous deployment of between 8 and 14 drifter units for up to 5 hours surrounding the low tide when the rip currents were most active.

The typical extent of the drifter deployment region was c. $500 \mathrm{~m}$ in the longshore and c. $300 \mathrm{~m}$ in the cross-shore direction. Drifters were individually seeded (rather than in clusters) along the shoreline to maintain both spatial and temporal coverage throughout the rip current system, maximizing the synoptic understanding of circulation patterns. Due to the rate of change of tidal elevation within a macrotidal regime, it was desirable to have drifter observations throughout the entire rip system at least every 30 minutes. Drifter deployments occurred every few days during the experiment periods providing observations throughout a range of wave, wind and tidal conditions (spring-neap and semi-diurnal). Drifter deployments were not logistically possible under large wave conditions $\left(H_{s}>\right.$ $3 \mathrm{~m}$ ) due to difficulties in drifter retrieval and monitoring. Austin et al. (2013) provides a detailed description of the drifter experiments and post-processing, and Schmidt et al. (2003), Spydell et al. (2007), and MacMahan et al. (2009) provide more information on the drifter design and validation of using low-cost GPS technology within a surf zone environment. The drifter units used here are a modification on the design of Schmidt et al. (2003) and MacMahan et al. (2009) to incorporate a modular and more robust construction.

Drifter data were post-processed against a reference GPS base station to provide positional information and deployments were split into flood and ebb tide segments as significant changes in forcing conditions often occurred over a full tidal cycle. Previous studies at Perranporth (Austin et al., 2010) have clearly shown that a distinct rip activation threshold exists relating to wave breaking (wave height and depth) over the inner bar crest, typically at c. $3 \mathrm{~m}$ depth. Above this threshold, minimal wave breaking occurs over the bar/rip morphology and the surf zone translates landward over the more morphologically subdued mid and upper beach face. It was important for this analysis that only drifter data that fell within this rip activation period were considered.

\section{Controls on rip current hazard}

\subsection{Incident severity}

The incident records presented here are from twenty selected seasonal lifeguard units run by the RNLI between March and October over the period 2006-2010 (Fig 4). While this period does not include the highest energy wave events that occur during the winter months, Fig 4 shows that the west coast of Devon and Cornwall still experiences a broad range of wave conditions throughout the remainder of the year, with seasonal summer $H_{50}$ between $1.0 \mathrm{~m}$ and $1.2 \mathrm{~m}$, and $H_{10}$ of $1.9 \mathrm{~m}$ to $2.4 \mathrm{~m}$ (Table 1 ). Seasonal coast-wide incident totals (all 20 beaches) range from 879 in 2006 to 1548 in 2007. Seasonal values for mean daily incidents are on the order of 0.5 incidents per beach. The typical number of people in the surf zone throughout the season remains relatively constant between 50 (2008) and 85 (2010) with the coast-wide daily surf zone population peaking at 6804 during 2009 (Fig 4). While it is hypothesised that hydrodynamic forcing has a significant effect on incident occurrence, surf zone population numbers control the exposure to rip current hazards and are likely to be controlled by additional regional factors such as weather (sunshine hours, rainfall rates and cloud cover), timing of holiday periods and weekends.

To account for the role of exposure to hazard, a subset of high-risk days was created for further analysis. For each beach, daily rip incident totals $\left(I n c_{r i p}\right)$ were normalized by the daily mean surf zone population $(P)$ recorded for that beach. Normalized rip incident totals for each beach $\left(\right.$ Inc $\left._{\text {rip }} / P\right)$ were then combined to provide a time series of coast-wide incident levels adjusted for local population exposure to rip hazards $\left(\Sigma\left(I n c_{\text {rip }} / P\right)\right)$. This provided the best available daily value for coast-wide rip risk (Fig 4). The daily values of coast-wide rip risk that exceeded the 95th percentile of the normalised dataset were included in the high-risk subset, consisting of 34 days and 1238 incidents across 20 beaches over 5 years. Many of these high-risk days were associated with incident totals exceeding 50 individuals, up to a maximum of 201 in 2010. The vast majority of these daily events, which henceforth will be referred to as 'Mass Rescue' $(M R)$ events, involve $>5$ beaches and are therefore likely to represent regional highrisk scenarios. [FIGURE 4][TABLE 1]

\subsection{Environmental conditions}

The frequency distributions of hindcast environmental parameters associated with all recorded rip incidents were examined to investigate the relationships between rip current forcing and hazard. To help identify the hazardous rip conditions, the environmental conditions during which incidents occurred were compared with the 'average' background conditions over the patrol season (3-hr resolution). This was carried out by comparing the average frequency distribution of specific environmental parameters (e.g., wave height, tide level, wind speed) with that computed from the environmental parameters associated with each recorded rip incident. Any significant difference between the distributions provides an indication of environmental conditions that may be driving rip hazards. For each environmental parameter, the background 'average' frequency distribution is compared to both the full incident dataset and the high-risk MR subset.

Daily low water elevation $L W$, relative to Ordnance Datum Newlyn (ODN), can be considered a proxy for tidal range. $L W$ controls the morphological expression and the rate of shoreline translation with low water being an important period of stationarity in water level. Significant 
peaks in the incident distributions occur around mean low water (approx. $-2.2 \mathrm{~m} \mathrm{ODN}$ ) indicating that tidal range has a significant control on rip incident levels (Fig 5). The peak in the MR distribution at $2.2 \mathrm{~m} \mathrm{ODN}(+/-0.125 \mathrm{~m})$ accounted for $38 \%$ of the total distribution, which is $23 \%$ above background (Fig 5). A peak in incidents during days when low water elevation is around MLW is found throughout all regions within the study area. These data support the hypothesis that the nearshore bar/rip morphology generates the most hazardous conditions when the water level is around the MLW level across the open-coast beaches in the study. Exposure to peak rip activity is prolonged when $L W$ is at MLW due to surf zone stationarity. [FIGURE 5]

Hindcast values of $H_{s}, T_{p}$ and $D_{m}$ are used to investigate wave forcing controls on rip incident occurrence (Fig $6)$. The frequency distributions of the wave parameters related to reported incidents show some significant differences from the average background distributions in both the full incident distribution and the high-risk MR subset.

Conditions of $H_{s}=0.75-1.25 \mathrm{~m}$ are significantly overrepresented (14\%) in the incident distributions, compared to the background distribution. It is also important to note that half the incidents occurred within this range $(49 \%)$. During MR incidents, the proportion of $H_{s}$ above background in even greater $(22 \%)$ occurring between $H_{s}$ values of 0.25 and $1.0 \mathrm{~m}$. The $66 \%$ of MR incidents occurring within this range represent high-risk high-exposure conditions. A smaller peak at $H_{s}=2.5-2.75 \mathrm{~m}$ is associated with high-risk low-exposure conditions when beach populations were low. The distribution of incident-related $T_{p}$ is not significantly different from the background when considering all incidents, but under high-risk MR days there is an identifiable shift to higher peak periods. The pivot point is at $T_{p}=10 \mathrm{~s}$, above which MR incident $T_{p}$ was $25 \%$ greater than background. Further analysis of the $H_{s^{-}}$ $T_{p}$ joint distribution shows that the highest $T_{p}$ peak at $16-18 \mathrm{~s}$ is entirely associated with values of $H_{s}$ below 0.5 $\mathrm{m}$. There was also a significant over-representation of incidents (all and MR subset) associated with a shore-normal angle of incidence. Finally, in both datasets, incidents occurring at mean wind speeds $\left(W_{s m}\right)$ below $5 \mathrm{~m} \mathrm{~s}^{-1}$ were over-represented with respect to the background, with values of $17 \%$ and $34 \%$ for all and MR incidents, respectively.

The analysis of 6458 lifeguard incident records coupled with site-specific hindcast hydrodynamic conditions over the period 2006-2010 has shown that environmental forcing has a significant control on high-risk rip incidents that occurred within the study region. Results show that highrisk and high-exposure scenarios occur disproportionately on days with low water elevation around MLW, low wave height $\left(H_{s}<1 \mathrm{~m}\right)$, large wave period $\left(T_{p}>10 \mathrm{~s}\right)$, shorenormal wave direction and light winds $\left(W_{s m}<5 \mathrm{~m} \mathrm{~s}^{-1}\right)$. The next step in the analysis is to improve our understanding of the physical rip current dynamics occurring under these conditions and explain why these conditions lead to increased rip risk. [FIGURE 6]

\section{Controls on rip current circulation}

The following section will discuss the results of the field experiments to help understand the rip current dynamics of the high-risk environmental conditions identified in the previous section on the RNLI lifeguard incident analysis.

\subsection{Environmental conditions}

Observations of rip current behaviour comprised forty 2-hour drifter deployment datasets collected over 25 days throughout May, June and October 2011 at Perranporth beach. The environmental conditions experienced during these two experiments are summarized in Fig 7 . The deployments experienced the full spring/neap tide ranges from 2.7 to $7.5 \mathrm{~m}$ with low water elevations varying by 2.2 $\mathrm{m}$. Significant periods of high energy waves occurred during the observation period $\left(H_{\max }>5 \mathrm{~m}\right)$, but the range of wave conditions during drifter deployment was restricted to $H_{s}=0.6-2.1 \mathrm{~m}$ due to logistical constraints under high energy conditions. Importantly, a broad range of wave periods, $T_{p}=4-13 \mathrm{~s}$ were observed during drifter deployments, covering both wind sea and swell wave conditions with spectral width $\epsilon$ ranging from 0.61 to 0.90 . The angles of wave approach varied from $\pm 12^{\circ}$ to shore-normal. Wind speeds (sourced from the UK Met Office; measured at $10 \mathrm{~m}$ height and averaged over 10-min intervals) were between 1.1 and $8.7 \mathrm{~m} \mathrm{~s}^{-1}$ for drifter deployment periods with the maximum onshore and offshore component wind velocities of 8.3 and $6.3 \mathrm{~m} \mathrm{~s}^{-1}$, respectively (UK Meteorological Office, 2011). The Lagrangian dataset collected encompasses a wide range of conditions, but, naturally, does not cover every conceivable combination of wave, wind and tidal state. [FIGURE 7]

During the field experiments, the bar and rip channel morphology are considered to be static within the context of seasonal and inter-annual beach change. However, the changing tide level over the three-dimensional morphology has a direct effect on wave dissipation patterns and rip flow constriction. The changing hydrodynamic conditions over a tidal cycle can, therefore, be interpreted in terms of a changing morphology. The concept of an 'active morphological template' is useful for understanding the increased importance of tidal range in controlling rip dynamics on macrotidal beaches (Austin et al., 2010; Scott et al., 2011b). Tidal range, and specifically low water elevation, act as a significant morphological control on the observed systems, and this is illustrated well by the crossshore displacement of MLWS and MLWN, and the drying of the inner bar system at MLWS. Fig 8 provides an example of the beach morphology during June 2011, highlighting key morphological features. Flows through the studied open-coast beach rip systems can be broken morphologically into four defined regions: (1) a feeder channel, (2) rip neck, (3) rip head and (4) an onshore flow over the inner bar crest (Fig 8). [FIGURE 8] 


\subsection{Lagrangian circulation}

The behavioural characteristics of the individual surf zone drifter tracks (logged at $1 \mathrm{~Hz}$ ) were analysed. The deployment examples in Fig 9, each representing $>150$ independent drifter tracks, illustrate three contrasting dominant deployment group-averaged drifter behaviours: alongshore, rotation and exit dominated. A drifter was deemed to have entered the rip circulation when it passed through regions 1 and 2 (Fig 8) and was classified as a rip 'rotation' (RO) when it remained within the surf zone and an 'exit' (EX) if it passed seaward of the calculated offshore extent of the surf zone. A classification of 'alongshore' (AL) was allocated when it followed the bathymetric contours in an longshore direction out of the study area without entering the rip. A single drifter track could display more than one behaviour: for example, it could complete one or more full rotations of the rip current and then exit the surf zone.

The limits of the surf zone were defined using modelled wave dissipation maps of the nearshore region (cf. Austin et al., 2013). The offshore extent of the surf zone was the location where the alongshore-averaged cross-shore roller energy, a proxy for wave breaking induced intensity (Aarninkh et al., 2003; Reniers et al., 2009), exceeds $10 \%$ of its crossshore maximum. Surf zone extent (and associated mean wave dissipation maps) was computed every 30 minutes to account for tidal translation.

Throughout all 40 drifter deployments surf zone exits ranged from 0 to $73 \%$. By contrast, deployments dominated by rotational behaviour peaked at $93 \%$. The third dominant behaviour was alongshore (not entering rip circulation) that reached a maximum of $71 \%$. Varying tidal range (controlling morphological influence of outer bar) and wave energy meant that surf zone widths varied from 99 to $317 \mathrm{~m}$ during deployments.

Offshore-directed Lagrangian rip current velocities $U_{\text {rip }}$ were also calculated within the rip neck region. The rip region was defined morphologically through thresholding of the linear detrended residual bathymetry. Maximum and median 30-min averaged $U_{\text {rip }}$ were 0.61 and $0.43 \mathrm{~m}$ $\mathrm{s}^{-1}$, respectively. When combined with the alongshore component of flow, maximum resolved 30-min averaged rip neck flow speed $U r_{\text {rip }}$ was $1 \mathrm{~m} \mathrm{~s}^{-1}$. However, $U_{\text {rip }}$ was used in the following analysis as it most effectively defined rip current activity without the combination of the alongshore current flowing through the inner trough.

This approach does not identify temporal fluctuations in rip flow or circulatory behaviour on temporal scales of less than 30 minutes as the spatial coverage of the drifter observations was too sparse to gain sufficient statistically significant velocities or drifter tracks. Instead, the following analysis focuses on dominant rip current behaviours over 2-hour periods and thus represents time-averaged behaviour.

\subsubsection{Analysis of behavioural groups}

To enable the investigation of key controls on dominant drifter behaviours, the measured drifter days were classified into the three behavioural groups. Distinction between the different patterns was supported by k-means cluster analysis (using the MATLAB software package), which separated deployments by those either above $15 \%$ exits or those below the exit threshold and proportionally dominated by AL or RO behaviour. [TABLE 2][FIGURE 9]

Canonical Discriminant Analysis (using the MATLAB software package) was used to determine which selected variables, if any, were best able to discriminate between the three behavioural groups (Jones, 2012) (Table 2). Forcing variables analysed were wave height $\left(H_{s}\right)$, peak wave period $\left(T_{p}\right)$, peak wave direction $\left(D_{p}\right)$, low water elevation $(L W)$ and cross-shore $\left(W_{u}\right)$ and alongshore $\left(W_{v}\right)$ velocity components of the mean wind speed $\left(W_{s m}\right)$.

A correlation matrix of all measured variables was initially calculated in order to remove those shown to be inter-correlated. Canonical Discriminant Analysis (CDA) is a dimension-reduction technique related to principal component analysis and canonical correlation. It derives canonical coefficients and finds linear combinations of the quanofitative variables that provide maximal separation between the classes in much the same way that principal components summarise total variation. The larger the standardised canonical coefficient (normalised orthogonal eigenvector), the greater the contribution of the respective variable to the discrimination between groups. Bartlett's approximate chi-squared statistic indicates that both discriminant functions were significant at the 0.05 level.

Fig 9 plots the canonical scores with $80 \%$ confidence ellipses. The confidence ellipses indicate that there is good discrimination between the three behavioural types. There are three groups in this analysis and, therefore, two canonical functions. The first canonical function (Axis I) explains $71.6 \%$ of the variance between the groups (Table 2). It represents the discrimination between the AL-dominated and RO/EX groups. The canonical coefficients suggest ALdominated conditions are separated from RO/EX events by smaller tidal ranges and more oblique wave directions (increase in wave direction is increase in angle from shorenormal) and to a lesser extent higher wave conditions. Wind velocities were the least important discriminators. The second canonical function (Axis II), orthogonal to the first, explains the variance between the RO and EX groups. In this dataset, exit events are most strongly differentiated by smaller tidal ranges, reduced wave heights and to a lesser extent higher peak wave period. While wind velocities were a greater contributor than wave direction, they where less significant than all other wave/tide factors.

\subsubsection{Wave and tidal control on circulation}

The primary variables highlighted in the CDA are further examined in Fig 10. As described in Function 1 (Table 2 ), the distinction of AL-dominated deployments from the others (EX and RO) was examined as a function of $L W$, $D_{p}$ and $H_{s}$. The AL behaviours mostly occurred during the smallest tides (neap tides; $L W>-1.6 m O D N$ ) and 
were strongly associated with relatively high angles of incidence $\left(D_{p}>10^{\circ}\right)$. As expected, AL conditions are associated with lower $U_{\text {rip }}$ velocities as alongshore currents dominate. AL-dominated deployments represent days when the rip systems were either not active or were overrun by the alongshore current. It was therefore important to consider the combined effect of $L W$ and $H_{s}$ which controlled the depth over the inner bar crest at low water and therefore dictated the wave height required to drive ('switch on') the rip systems. Under the smallest tide ranges (neap tides) limited wave breaking over the bar/rip system reduced or 'switched off' rip currents allowing the alongshore current to dominate. At the other extreme, $75 \%$ of AL deployments occurred when $H_{s}>1.8 \mathrm{~m}$ when the majority of waves were breaking on the outer bar, driving strong alongshore currents within the surf zone and reducing rip current circulation.

The combination of Function 1 and 2 explains the variance between RO and EX groups (Table 2). Fig 10 shows that the two groups can be effectively separated by $H_{s}$ and $L W$. There is a wave height transition at around $H_{s}=1 \mathrm{~m}$, below which EX groups dominate and above which RO groups dominate. This transition appears to be modified by low water elevation, where lowering $L W$ (reducing water depth over inner and outer bar crests at low tide) reduces the wave height threshold above which RO dominates. The combination of these two controlling variables suggests that a wave breaking criterion (a combination of $H_{s}$ and $L W$ ) may have some skill in defining the division between these two behaviours. It is worth noting that within EX deployments, $U_{\text {rip }}$ values tend to reduce as the proportion of exits increase. RO and EX deployments were also effectively separated by $D_{p}$ with EX and RO deployments occurring with $D_{p}$ between $-10^{\circ}$ and shorenormal and between shore-normal and $15^{\circ}$, respectively.

It is the factors controlling the development of $\mathrm{RO}$ or EX dominated behaviours that are of key importance for furthering our understanding of rip hazards. The environmental parameters on their own are reasonably successful in distinguishing between the different rip circulation types. However, by combining certain parameters, physically more meaningful parameterisation can be arrived at. Testing of various combinations of $H_{s}, T_{p}$, and $L W$ led to the selection of $H_{s} / h$, a recognised wave breaking parameter, where $\mathrm{h}$ is the water depth over the outer bar at low water $L W$, and $H_{s} T_{p}$ as the most effective way to separate EX and RO behaviour (Fig 10; lower panel). Reniers et al. (2009) also reported that $H_{r m s, 0} T_{m 01}$, a component of exit parameter $E$ (Equation 1) was highly correlated with exit percentages in their measured and modelled datasets from beaches in California. [FIGURE 10]

Fig 11 shows the distribution of exit percentages of all EX and RO deployments as a function of $H_{s} T_{p} / \overline{H_{s} T_{p}}$ (hereon referred to as the 'wave factor' $W_{f}$ ), which describes the ratio between the associated $H_{s} T_{p}$ and the 5 year seasonal (April - October) mean $\left(\overline{H_{s} T_{p}}\right)$. Exit percentages decrease with increasing $W_{f}$ until $W_{f}=1$, after which all exits values are $<10 \%$, indicating that exit percentages increase once the wave factor drops below the long-term seasonal mean. The least square fit between \%exit and $W_{f}$ gives an $R^{2}$ of 0.71 . [FIGURE 11]

Making the assumption that the length scales of the morphological template (scale and elevation) at mean low water are in a long-term equilibrium with a seasonal $\overline{H_{s} T_{p}}$, the response of measured exit percentages as a function of $W_{f}$ would support a hypothesis similar to that of MacMahan et al. (2010) for single-barred beaches; that with decreasing wave energy, wave breaking on the outer bar and rip head is reduced and the rip circulation becomes decoupled from the full morphological template leading to increased rip current exits. The increased exit behaviours occur as the rip circulation is driven by wave breaking around the inner bar morphology with intermittent or no breaking on the outer bar. Therefore the surf zone and active morphological template are narrowed as the outer bar is effectively removed from the process domain.

It follows on that modifying $L W$ will affect the nature of the active morphology by increasing and decreasing the depth over the bar crests. It was desirable to incorporate a variable that was readily available to describe the tidal control on the active morphology; therefore, $L W$ was used rather than $h$ because the measurement of depth over the bar crest outside of a scientific field campaign was impractical.

Observations thus far have indicated that $L W$ is strongly related to exit percentages. Fig 11 shows that most EXdominated deployments ( $>15 \%$ exits) occurred within approximately $0.5 \mathrm{~m}$ of MLW $(\overline{L W})$, particularly where $W_{f}<1$ (less than the seasonal average). As $L W-\overline{L W}$ (hereon referred to as the 'tide factor' $T_{f}$ ) drops below 0.5 $\mathrm{m}$, exit percentages rapidly decrease, but rip current flows remain high within the rip neck. Offshore-directed rip current flow velocities increased with wave energy from $W_{f}=$ $0.3-0.8$ beyond which there was no trend. Interestingly, as flow velocities increase with $W_{f}$, exit percentages decrease until $W_{f}=1$, beyond which exit percentages are low. Importantly, there is an overlap where exits are high and rip currents are relatively strong between $W_{f}=0.6-0.8$.

\subsubsection{Morphological variability}

While the water level elevation at which low-tide rip current morphology was most active during the field experiments was around the MLW level, it was important to quantify the potential variability in this morphological system if the findings are to have meaning beyond the observed period. To identify whether the studied rip morphology was representative in the context of multi-annual variability at Perranporth, two years of bathymetric profiles were analysed to assess the morphological variation of the mean cross-shore profile (Fig 12). [FIGURE 12]

Measured exit behaviours are controlled by the distribution of wave energy dissipation across the active morphological template. Particularly, most exit events were constrained between low water elevations -2.5 to $-2 \mathrm{~m}$ 
ODN, suggesting that bar morphology was the primary control of rip current behaviour and that there was a morphological template that preferentially drove rip current exits that was maximised around mean low water $(-2.2 \mathrm{~m}$ ODN at Perranporth).

The evolution of the mean cross-shore bar morphology at Perranporth, measured at approximately 6 -week intervals between 2010 and 2012, indicates that the inner and outer bars migrate onshore and offshore and fluctuates in elevation seasonally. The inner bar appears to be more stable than the outer bar. Throughout the dataset the range of mean inner and outer bar elevations, is $1.1 \mathrm{~m}$ and $1.3 \mathrm{~m}$ (standard deviations of 0.33 and $0.42 \mathrm{~m}$ ), respectively (Fig 12). The mean inner bar elevation is $1 \mathrm{~m}$ below MLW indicating that under all but the smallest wave conditions wave breaking would occur over the inner bar system at MLW. This indicates that at MLWS, the mean inner bar elevation would be in the inner surf/swash zone under moderate energy conditions. The mean outer bar elevation ( $2.1 \mathrm{~m}$ below MLWS) is at a depth over which moderate waves would break at MLWS and extend the surf zone width.

Analysis of the bathymetric dataset shows that the inner bar/rip system is typically present around MLW. This is the region of the beach over which the surf zone resides for the longest; therefore, it may come as no surprise that rip current morphology, which evolves from surf zone derived cell-circulation, commonly occurs at this beach elevation.

\subsubsection{Modes of rip circulation}

The controls on rip current circulation observed in this study can be broken down into two primary factors: wave energy and the active morphology (tide). These two factors combine to control the spatial distribution of wave dissipation and wave transformation across the surf zone which in turn controls rip circulation and flow speeds. Analysis of the Lagrangian data and measured boundary conditions have been synthesised in Fig 13 to provide a conceptual overview of the observed rip dynamics throughout the $W_{f}-T_{f}$ parameter space. The schematic diagrams in Fig 13 are supported by hydrodynamic model output generated from XBeach using measured bathymetry from June 2011 (Austin et al., 2013). XBeach is a depth-averaged wave group-resolving model that was calibrated and validated for Perranporth.

The bathymetric time series at Perranporth indicates that the morphological template responsible for the inner bar rip current systems is consistently located around MLW and as the water level drops to MLWS the outer bar (including rip head bar) becomes increasingly active. Therefore the transition from dominant wave breaking (under mean wave conditions) over the bars adjacent to the rip neck at MLW to the outer bar, can be modulated by both $W_{f}$ and $T_{f}$ (Fig 13).

At Perranporth, it was under wave energy conditions greater than the mean that surf zone exits were typically at a minimum. We suggest that this behavioural change is caused by a combination of wave breaking at the rip head bar driving secondary circulation associated with the outer bar and enhanced Stokes drift that is maximised over the outer bar, reducing offshore Eulerian velocities at the outer edge of the surf zone. Stokes Drift is a function of wave amplitude and frequency such that it is proportional to $H_{s}^{2} T_{p}$ providing an explanation why, in addition to wave breaking over the rip head/outer bar, $H_{s} T_{p}$ has a strong negative correlation with observed exit percentages. Modelling studies by Reniers et al. (2009) and Austin et al. (2013) using a wave group-resolving computational approach assessed the contribution of Generalised Lagrangian Mean (GLM) velocity, and thus the effect of Stokes drift on rip circulation, particularly surf zone retention. Both studies identified the importance of accounting for Stokes drift in the successful computation of observed Lagrangian behaviours. Without the inclusion of Stokes drift, the majority of virtual drifters released exited the surf zone under Eulerian flows. Therefore this dataset supports earlier measured and modelled datasets in identifying Stokes drift as a critical mechanism for retaining material in the surf zone and reducing surf zone exits to observed levels.

Fig 13 illustrates that in addition to its control of rip circulatory behaviour, increased wave energy caused an increase in rip flow speeds as well as the cross-shore length scale of the circulation. This is likely to have a significant effect on bathing hazard as modelled rip flow speeds in the inner surf zone reach a maximum under mean wave energy conditions $\left(W_{f}=1\right)$ and $T_{f}=0-0.5 \mathrm{~m}$ when the rip circulation appears coupled to the underlying morphology. A further increase in wave factor or decrease in water level resulted in the activation of separate rip systems over the outer bar which reduced the rip current intensity over the inner bar. Similar relationships between the tidally-modulated active morphology and wave height, relating specifically to rip flow velocities, were observed in French meso- to macrotidal double bar systems by Castelle et al. (2006) and Bruneau et al. (2009) where Castelle et al. (2007) also identified the importance of considering the influence of the outer bar in the morphodynamics of the rip system. [FIGURE 13]

Four modes of rip behaviour were identified at Perranporth which provide insight into the physical controls on rip hazards on macrotidal LTBR beaches.

Mode 1: Low to moderate energy $\left(W_{f}=0.2-0.5\right)$ with a relatively narrow surf zone. The active morphological template is associated with either small neap tide ranges $\left(T_{f}>=0.5 \mathrm{~m}\right)$ or low wave energy. Flow speeds are low but rip exits are high due to a narrow surf zone and insignificant onshore flows at the outer edge of the surf zone. Under these conditions wind-generated flows become important as they can be of the same order of magnitude as surf zone currents. As $W_{f}$ increases, rotational rip circulations begin to establish. This mode represents the transition to rip current inactivity. A reduction of $W_{f}$ or increase in $T_{f}$ would 'switch off' the rip current. 
Mode 2: Moderate energy $\left(W_{f}=0.5-1\right)$ with occasional breaking on the offshore bar. The active morphological template is associated with smaller tide ranges $\left(T_{f}=0-0.5 \mathrm{~m}\right)$, where the combination of rip exits and flow speed is maximised, especially in the higher energy case $\left(W_{f}=1\right)$. The cross-shore length scales of the rip circulation almost extend to the outer bar. Strong retentive eddies occur either side of rip neck (strong onshore flows over shoals) but limited breaking occurs over the rip head/outer bar to reduce the exit numbers. Rip flows are almost shore-normal at the surf zone edge reducing alongshore deflection to the shoals (onshore transport dominated regions) so that rip exits level are relatively high in comparison to rotation.

Mode 3: Moderate energy $\left(W_{f}=0.5-1\right)$ with a full width surf zone including persistent breaking on the outer bar. Rip flows are medium-high, and increased rotational behaviour leads to less exits than Mode 2. This mode encompasses the long-term seasonal mean condition where $W_{f}=1$ and $T_{f}=0 \mathrm{~m}$. Rip cross-shore length scales are coupled to morphology and outer bar rip systems are active leading to the potential for transport far beyond the surf zone edge. At the lowest water levels $\left(T_{f}=-0.5 \mathrm{~m}\right)$ inner feeder channels and bars began to dry out leading to a constriction in the inner bar rip circulation length scale. A key feature is the increased presence of a meandering longshore current linking adjacent rip cells, but constrained within the inner surf zone. Shore-normal rip flows are still sufficiently dominant to drive a relatively high proportion of rip exits.

Mode 4: Moderate to high energy $\left(W_{f} \geq 1\right)$ dominated by wave breaking on the outer bar. Exit levels are low for inner surf zone released drifters. This mode occurs when either the tidal level is very low $\left(T_{f} \leq 0.5 \mathrm{~m}\right)$ associated with spring tides, or the wave energy is above average $\left(W_{f} \geq 2\right)$. The active morphological template includes both the inner and outer bars and the inner rip cells are isolated in a saturated surf zone where the outer rip cells are the dominant feature. Strong alongshore currents dominate in the inner surf zone, meandering around isolated morphological 'holes' that are associated with weak rotation eddies.

\section{Discussion and Conclusions}

Results from the analysis of rip dynamics at Perranporth have highlighted how wave energy and water level acting on the nearshore bar-rip morphological template are key controls on the type of rip circulation. Recent rip current studies (MacMahan et al., 2011; McCarroll et al., 2013) have suggested that, in addition to the traditional association with flow speed, the circulatory behaviour of a surf zone drifter has a significant relevance for the level of rip current hazard to which a bather may be exposed. The incident data presented in this paper provided a unique opportunity to test this hypothesis, because they enabled a comparison between our identified rip current Lagrangian controls from Perranporth with levels of measured rip hazards from multiple beaches with similar morphology within our study region (Fig 14).

Fig 14 compares the 'average' background distribution of the two composite environmental parameters $W_{f}$ (wave factor $=H_{s} T_{p} / \overline{H_{s} T_{p}}$ ) and $T_{f}$ (tide factor $=L W-$ $\overline{L W}$ ), identified as key controls on rip behaviour, against their distributions that are associated with recorded rip incidents (2006-2010; 20 beaches). A disproportionate amount of rip incidents and MR events (high-risk incidents) took place on days when the low water level was close to MLW ( $\left.T_{f}=0 \pm 0.2 \mathrm{~m}\right)$. Rip current observations at Perranporth indicated that this elevation was also associated with exit dominated behaviours, particularly with wave conditions less energetic than the seasonal term average $\left(W_{f}<1\right)$. However, while surf zone exit percentages increased further as $W_{f}$ decreased, the incident related distribution showed a significant peak above the background distribution for $0.6<W_{f}<1.1$ just below the seasonal average, with maximum peak at 0.8 . A significant reduction in incidents occurred above and below this range (Fig 14). [FIGURE 14]

Drifter deployments with the lowest $W_{f}$ values were also associated with the lowest offshore rip flow velocities. It is evident that there is a minimum level of wave energy required to drive hazardous rip current flows as there is a sharp reduction in rip incidents below $H_{s} T_{p} / \overline{H_{s} T_{p}}=0.6$. Therefore the data would suggest that a combination of both rip circulatory behaviour and flow speed combines to produce an optimum scenario raising levels of rip hazard.

High-risk high-exposure conditions are represented by Mode 2 and high-flow Mode 3 rip behaviours (Fig 13). While surf zone flow speeds probably increase with $W_{f}>1$ , the inner surf zone becomes increasingly dominated by alongshore currents and the stronger outer bar rip cells are less accessible to the bather, therefore the potential exposure to the hazard is reduced. In addition, it is suggested that the surf zone wave and current hazards become more obvious to the public as the wave energy increases and waves become higher, acting as a deterrent to entering the surf zone. There will also be a wave energy threshold above which lifeguard patrols will close the beach to bathers as part of routine beach safety management procedures.

The identified controls on rip hazard would appear to have relevance beyond Perranporth beach, as the incident signal represents a combined dataset of 20 beaches within the study region. In fact, the concept of the importance of the active rip current morphology being associated with the MLW region (low-mid tide) is also supported in recent studies of the meso-macrotidal French Aquataine coast (Castelle et al., 2006; Bruneau et al., 2009) where measured rip flows are maximised between low-mid tide, but reduce and in some cases cease at spring low water. This suggests that the use of a tide factor may be portable to other tidal environments. Interestingly, the exit thresholds $\left(T_{f} \pm 0.5 \mathrm{~m}\right)$ observed in Perranporth, above and below which surf zone exits are reduced, would not often be ex- 
ceeded in microtidal environments which do not experience the extremes in tidal level.

Significant knowledge gaps still remain, particularly in testing these forcing controls in other beach environments, both regionally and internationally. While a range of wave and tidal conditions were observed, the underlying morphology in this study was assumed to be relatively static. It is known that morphological state is constantly evolving (e.g., Wright and Short, 1984; Castelle et al., 2007) and while length scales may remain the same, threedimensional configuration may change dramatically in response to forcing. The conceptual rip behavioural model presented in Fig 13 represents a starting point, which needs to be tested and populated with data, both measured and modelled, for a range of morphologies and coastal settings to gain further insight into the role of morphology in controlling rip behaviours and hazards.

It must also be considered that this study has focussed on mean rip current behaviours over two-hour periods. Flow and behavioural variability at higher frequencies are also known to be significant in contributing to levels of rip current hazard (Dalrymple et al., 2011; MacMahan et al., 2011). These typically manifest as wave-group driven infragravity $(0.004-0.04 \mathrm{~Hz} ; 25-250 \mathrm{~s})$ and very low frequency (VLF) (0.0005-0.004 Hz; 4-30 min) velocity signals. Rip pulsing has been observed at Perranporth at VLF frequencies during the field experiments (Thorpe et al., 2013). Although qualitative observations of rip current behaviour during the field experiments suggested temporal fluctuation of rip flows during the 2-hour deployments on some days, there were other days when behaviour was remarkably stable throughout the deployment. Further work must be done to assess the importance of temporal fluctuations in rip behaviour on hazard.

To conclude, a unique measured dataset of beach rip systems at a high-energy macrotidal beach with bar-rip morphology has been shown to be very useful in improving our understanding about the drivers of high-risk highexposure rip current scenarios observed over a 5-year period in southwest England. In fact, the key controlling factors of wave energy and active morphology (tidal elevation), identified to best describe measured rip behaviour at Perranporth, are also very effective at discriminating between observed coast-wide high-risk incident events. Analysis showed that high-risk open-beach rip currents occur at or below average wave conditions $\left(0.6<H_{s} T_{p} / \overline{H_{s} T_{p}}<\right.$ 1.1), with water levels around mean low tide and light winds $\left(<5 \mathrm{~m} \mathrm{~s}^{-1}\right)$. It is under these conditions that the rip circulation is characterised by the strongest seawarddirected flows and highest proportion of surf zone exits. Therefore this study has shown that there is a considerable element of environmental control associated with observed high-risk MR rip incidents and that neither the rip flow or rip circulatory behaviour can be viewed in isolation when considering rip current hazard; rather, it is the optimal combination of the two elements that drive high bathing risk.

\section{Acknowledgements}

We would like to thank our excellent field and technical team: Peter Ganderton, Anthony Thorpe, Claire Earlie, Ellie Woodward, Tim Poate, Robert McCall, Megan Sheriden, Ivan Burton, Richard Kenyon, Pedro Almeida, Hanna Richardson, Jak McCarroll, Kit Stokes, Barbara Proenca, Joana van Nieuwkoop, Ruth Stafford, Matt Hilton, Bruno Castelle, Nicolas Bruneau, Dano Roelvink, Ap van Dongeren, Leo Sembiring, Jack Puleo, Mark Davidson, Iain Fairley, Fran Sieck, Emily Beaumont and Jon Miles. We would also like to thank the RNLI, and in particular Dickon Berriman, for their assistance at Perranporth. Phil Maynard from the Perranporth YHA is also thanked for his ongoing assistance. This research was funded by the NERCRNLI partnership grant NE/H004262/1, Dynamics of Rip Currents and Implications for Beach Safety.

\section{References}

Aagaard, T., Greenwood, B., Nielsen, J., 1997. Mean currents and sediment transport in a rip channel. Marine Geology, 140 (1-2), 25-45.

Aarninkhof, S. G. J., Turner, I. L., Dronkers, T. D. T., Caljouw, M., Nipius, L., 2003. A video-based technique for mapping intertidal beach bathymetry. Coastal Engineering, 49 (4), 275-289.

Austin, M. J., Scott, T., Brown, J., Brown, J., MacMahan, J., Masselink, G., Russell, P., May 2010. Temporal observations of rip current circulation on a macro-tidal beach. Continental Shelf Research, 30 (9), 1149-1165.

Austin, M. J., Scott, T. M., Russell, P. E., Masselink, G. 2013. Rip Current Prediction: Development, Validation, and Evaluation of an Operational Tool. Journal of Coastal Research, 121012085426006.

Bowen, A. J., Inman, D. L., 1969. Rip currents 2. Laboratory and field observations. Journal of Geophysical Research, 74 (23), 54795490.

Bowen, J. A., 1969. Rip Currents 1. Theoretical Investigations. Journal of Geophysical Research, 74 (23), 5467-5478.

Brander, R. W., 1999. Field observations on the morphodynamic evolution of a low-energy rip current system. Marine Geology, 157 (34), 199-217.

Brander, R. W., Short, A. D., 2001. Flow kinematics of low-energy rip current systems. Journal of Coastal Research, 17 (2), 468-481.

Brander, R. W., Short, A. D., 2006. Morphodynamics of a largescale rip current system at Muriwai Beach, New Zealand. Marine Geology, 165 (2000), 27-39.

Brighton, B., Sherker, S., Brander, R., Thompson, M., Bradstreet, A., 2013. Rip Current Related Drowning Deaths and Rescues in Australia 2004-2011. Natural Hazards and Earth System Science, 14 (4), 1069-1075.

Bruneau, N., Bonneton, P., Castelle, B., Pedreros, R., 2011. Modeling rip current circulations and vorticity in a high-energy mesotidal-macrotidal environment. Journal of Geophysical Research, 116 (C7), 1-17.

Bruneau, N., Castelle, B., Bonneton, P., Pedreros, R., Almar, R., Bonneton, N., Bretel, P., Parisot, J.-P., Sénéchal, N., 2009. Field observations of an evolving rip current on a meso-macrotidal welldeveloped inner bar and rip morphology. Continental Shelf Research, 29 (14), 1650-1662.

Castelle, B., Bonneton, P., Dupuis, H., Sénéchal, N., 2007. Double bar beach dynamics on the high-energy meso-macrotidal French Aquitanian Coast: A review. Marine Geology, 245 (1-4), 141-159.

Castelle, B., Bonneton, P., Senechal, N., Dupuis, H., Butel, R., Michel, D., 2006. Dynamics of wave-induced currents over an alongshore non-uniform multiple-barred sandy beach on the Aquitanian Coast, France. Continental Shelf Research, 26 (1), 113-131. 
Castelle, B., Michallet, H., Marieu, V., Leckler, F., Dubardier, B. Lambert, A., Berni, C., Bonneton, P., Barthélemy, E., Bouchette, F., 2010. Laboratory experiment on rip current circulations over a moveable bed: Drifter measurements. Journal of Geophysical Research, 115 (C12), 1-17.

Dalrymple, R. A., MacMahan, J. H., Reniers, A. J. H. M., Nelko, V., 2011. Rip Currents. Annual Review of Fluid Mechanics, 43 (1), $551-581$.

Holman, R. A., Stanley, J., 2007. The history and technical capabilities of Argus. Coastal Engineering, 54 (6-7), 477-491.

Huntley, D. A., Hendry, D. M., Haines, J., Greenidge, B., 1988. Waves and rip currents on a caribbean pocket beach. Journal of Coastal Research, 4 (1), 69-79.

Jones, D. L., 2012. The Fathom Toolbox for Matlab: multivariate ecological and oceanographic data analysis. Available from http://www.marine.usf.edu/user/djones/matlab/matlab.html

MacMahan, J., Brown, J., Brown, J., Thornton, E., Reniers, A. J. H. M., Stanton, T., Henriquez, M., Gallagher, E., Morrison, J., Austin, M. J., Scott, T. M., Senechal, N., 2010. Mean Lagrangian flow behavior on an open coast rip-channeled beach: A new perspective. Marine Geology, 268 (1-4), 1-15.

MacMahan, J., Brown, J., Reniers, A. J. H. M., Brown, J., Thornton, E., Stanton, T., Henriquez, M., Gallagher, E., 2008. Lagrangian Observations on a Rip Channeled Beach, 1-5.

MacMahan, J., Brown, J., Thornton, E., 2009. Low-Cost Handheld Global Positioning System for Measuring Surf-Zone Currents. Journal of Coastal Research, 25 (3), 744-754.

MacMahan, J., Reniers, A. J. H. M., Brown, J., Brander, R., Thornton, E., Stanton, T., Brown, J., Carey, W., 2011. An Introduction to Rip Currents Based on Field Observations. Journal of Coastal Research, 274, iii-vi.

MacMahan, J. H., Reniers, A. J. H. M., Thornton, E. B., Stanton, T. P., 2004. Surf zone eddies coupled with rip current morphology. Journal of Geophysical Research, 109 (C7), 1-15.

MacMahan, J. H., Thornton, E. B., Reniers, A. J. H. M., 2006. Rip current review. Coastal Engineering, 53 (2-3), 191-208.

MacMahan, J. H., Thornton, E. B., Stanton, T. P., Reniers, A. J. H M., 2005. RIPEX: Observations of a rip current system. Marine Geology, 218 (1-4), 113-134

Masselink, G., Short, A. D., 1993. The effect of tide range on beach morphodynamics and morphology. Journal of Coastal Research, 9 (3), 785-800.

McCarroll, R. J., Brander, R. W., Macmahan, J. H., Turner, I. L., Reniers, A. J. H. M., Brown, J. A., Bradstreet, A., 2013. Assessing the effectiveness of rip current swimmer escape strategies, Shelly Beach, NSW, Australia. Journal of Coastal Research, Special Issue 65, 2013, 784-789.

McKenzie, P., 1958. Rip-current systems. Journal of Geology, 66 (2), 103-113.

Plant, N. G., Holland, K. T., Puleo, J. A., 2002. Analysis of the scale of errors in nearshore bathymetric data. Marine Geology, 191 (1-2), 71-86.

Prodger, S., 2012. Argus observations of rip current variability along a macro-tidal beach. Unpublished Master thesis, Plymouth University.

Reniers, A. J. H. M., MacMahan, J., Thornton, E., Stanton, T., 2006. Modelling infragravity motions on a rip-channel beach. Coastal Engineering, 53 (2-3), 209-222.

Reniers, A. J. H. M., MacMahan, J. H., Beron-Vera, F. J., Olascoaga, M. J., 2010. Rip-current pulses tied to Lagrangian coherent structures. Geophysical Research Letters, 37 (5).

Reniers, A. J. H. M., MacMahan, J. H., Thornton, E. B., Stanton, T. P., Henriquez, M., Brown, J. W., Brown, J. A., Gallagher, E., 2009. Surf zone surface retention on a rip-channeled beach. Journal of Geophysical Research, 114 (C10), 1-12.

Reniers, A. J. H. M., Roelvink, J. A., Thornton, E. B., 2004. Morphodynamic modeling of an embayed beach under wave group forcing. Journal of Geophysical Research, 109 (C1).

Schmidt, W. E., Woodward, B. T., Millikan, K. S., Guza, R. T., Raubenheimer, B., Elgar, S., 2003. A GPS-Tracked Surf Zone Drifter. Journal of Atmospheric and Oceanic Technology, 20 (7),
1069-1075.

Scott, T., Masselink, G., Russell, P., 2011a. Morphodynamic characteristics and classification of beaches in England and Wales. Marine Geology, 286, 1-20.

Scott, T., Russell, P., Masselink, G., Wooler, A., Short, A., 2008. High Volume Sediment Transport and Its Implications for Recreational Beach Risk. Coastal Engineering 2008 - Proceedings of the 31st International Conference 1-5, 4250-4262.

Scott, T. M., Russell, P., Masselink, G., Austin, M. J., Wills, S., Wooler, A., 2011b. Rip current hazards on large-tidal beaches in the United Kingdom. In Rip Currents: Beach Safety, Physical Oceanography, and Wave Modeling, CRC Press, Taylor \& Francis Group. pp. 225-242.

Scott, T. M., Russell, P. E., Masselink, G., Wooler, A., Short, A. D., 2007. Beach rescue statistics and their relation to nearshore morphology and hazards: a case study for southwest England. Journal of Coastal Research, SI 50, 1-6.

Shepard, F., 1949. Dangerous currents in the surf. Physics Today 2, 20-29.

Shepard, F. P., Emery, K. O., La Fond, E. C., 1941. Rip currents: a process of geological importance. Journal of Geology, XLIX, 337369

Short, A. D., 1999. Handbook of beach and shoreface morphodynamics. Chichester, UK: John Wiley and Sons.

Short, A. D., Brander, R. W., 1999. Regional variations in rip density. Journal of Coastal Research, 15 (3), 813-822.

Short, A. D., Hogan, C. L., 1994. Rip Currents and beach hazards: Their impacts on public safety and implications for coastal management. Journal of Coastal Research, (SI 12), 197-209.

Spydell, M., Feddersen, F., Guza, R. T., Schmidt, W. E., 2007. Observing Surf-Zone Dispersion with Drifters. Journal of Physical Oceanography, 37 (12), 2920-2939.

Thorpe, A., Miles, J., Masselink, G., Russell, P., Scott, T., Austin, M., 2013. Suspended Sediment Transport in Rip Currents on a Macrotidal Beach. Journal of Coastal Research, Special Issue 65, 1880-1885.

Tolman, H., Chalikov, D., 1996. Source terms in a 3rd generation wind-wave model. Journal of Physical Oceanography, 26, $2497-$ 2518 .

UK Meteorological Office, 2011. Met Office Integrated Data Archive System (MIDAS) Land and Marine Surface Stations Data (1853-current). NCAS British Atmospheric Data Centre. Available from http://badc.nerc.ac.uk/view/badc.nerc. ac.uk__ATOM__dataent_ukmo-midas

Wright, L. D., Short, A. D., 1984. Morphodynamic variability of surf zones and beaches: a synthesis. Marine Geology, 36, 93-118. 
Table 1: Summary of rip-related incident statistics recorded by the RNLI lifeguards between spring 2006 to autumn 2010. Data are from $20 \mathrm{LTT}+\mathrm{R}$ and LTBR beaches monitored for this study. Associated exceedence wave climate statistics that relate to seasonal patrol hours are shown.

\begin{tabular}{lllllllll}
\hline \multicolumn{2}{l}{ Seasonal } & & & & \multicolumn{4}{c}{ Daily (normalised by beach number) } \\
\hline Year & $\begin{array}{l}\text { Inc. } \\
\text { (total) }\end{array}$ & $\mathrm{H}_{50}$ & $\mathrm{H}_{10}$ & $\mathrm{~T}_{50}$ & $\mathrm{~T}_{10}$ & $\begin{array}{l}\text { Inc }_{\text {rip }} \\
(\text { mean })\end{array}$ & $\begin{array}{l}\mathrm{P}_{\text {surf }} \\
(\text { mean })\end{array}$ & $\begin{array}{l}\mathrm{P}_{\text {surf }} \\
(\max )\end{array}$ \\
\hline 2006 & 879 & 1.0 & 2.1 & 8.8 & 11.2 & 0.31 & 71 & 297 \\
2007 & 1548 & 1.1 & 2.2 & 8.9 & 11.2 & 0.52 & 74 & 570 \\
2008 & 1387 & 1.1 & 2.3 & 8.8 & 11.1 & 0.46 & 50 & 262 \\
2009 & 1215 & 1.2 & 2.4 & 8.8 & 11.1 & 0.39 & 68 & 296 \\
2010 & 1429 & 1.2 & 1.9 & 8.7 & 11.1 & 0.45 & 85 & 304 \\
\hline
\end{tabular}

Table 2: Results from Canonical Discriminant Analysis.

\begin{tabular}{lll}
\hline \hline \multicolumn{3}{l}{ Canonical discriminant functions (standarised) } \\
\hline Wave height (Hs) & Function 1 & Function 2 \\
Wave period (Tp) & -0.510 & 1.005 \\
Wave direction (Dp) & -0.561 & -0.738 \\
Low water elevation (LW) & -0.948 & 0.362 \\
Wind velocity cross-shore (Wu) & 1.311 & 1.254 \\
Wind velocity alongshore (Wv) & 0.330 & -0.606 \\
\multicolumn{2}{l}{ Percentages of within-group variance (\%) } \\
\hline
\end{tabular}




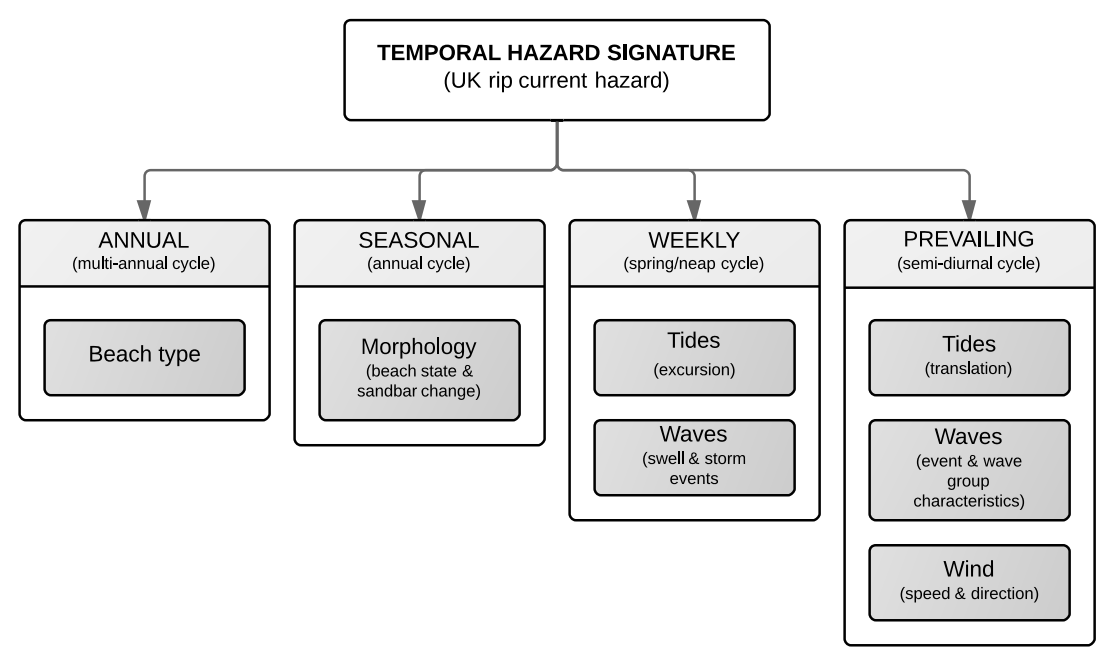

Figure 1: Diagram of the rip current 'Temporal Hazard Signature' (THS) and associated scales for macrotidal beaches studied in the United Kingdom. Principal environmental controls on rip hazards associated with each time scale are indicated. 


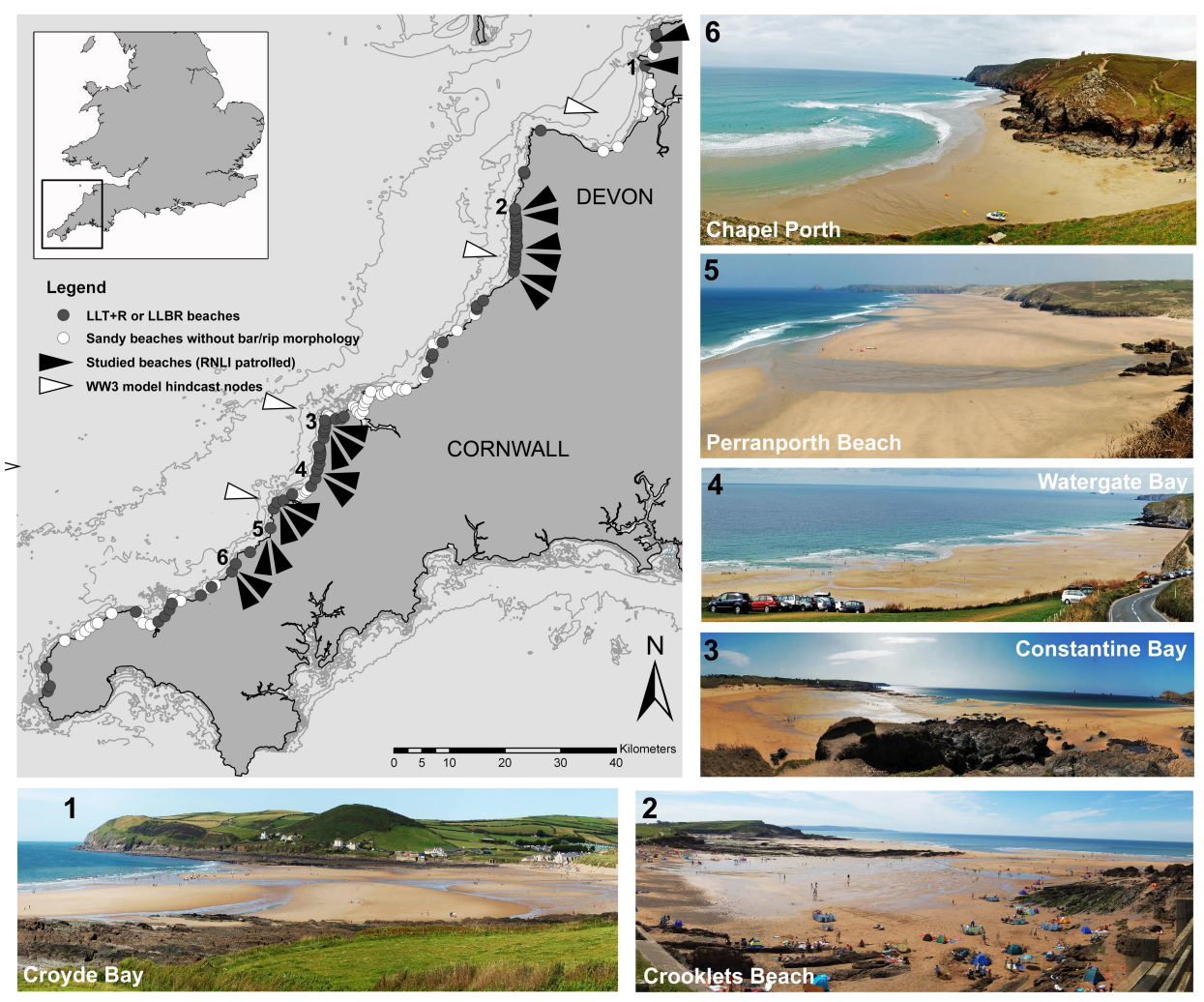

Figure 2: Overview of rip hazard study region. (Upper left panel) Map of the Cornwall and Devon in the southwest of England. Grey and white filled circles are all the sandy beaches along the west coasts of Devon and Cornwall with and without rip channel morphology, respectively. Arrows locate lifeguarded beaches with rip activity (LTT $+\mathrm{R}$ and LTBR beaches) used in this study (inset shows UK context). White arrows indicate beaches which are co-located with a hindcast wave model output. Photographs (numbered on map) illustrate examples of some of the study sites. Images show rip channel morphologies at spring low tide. 

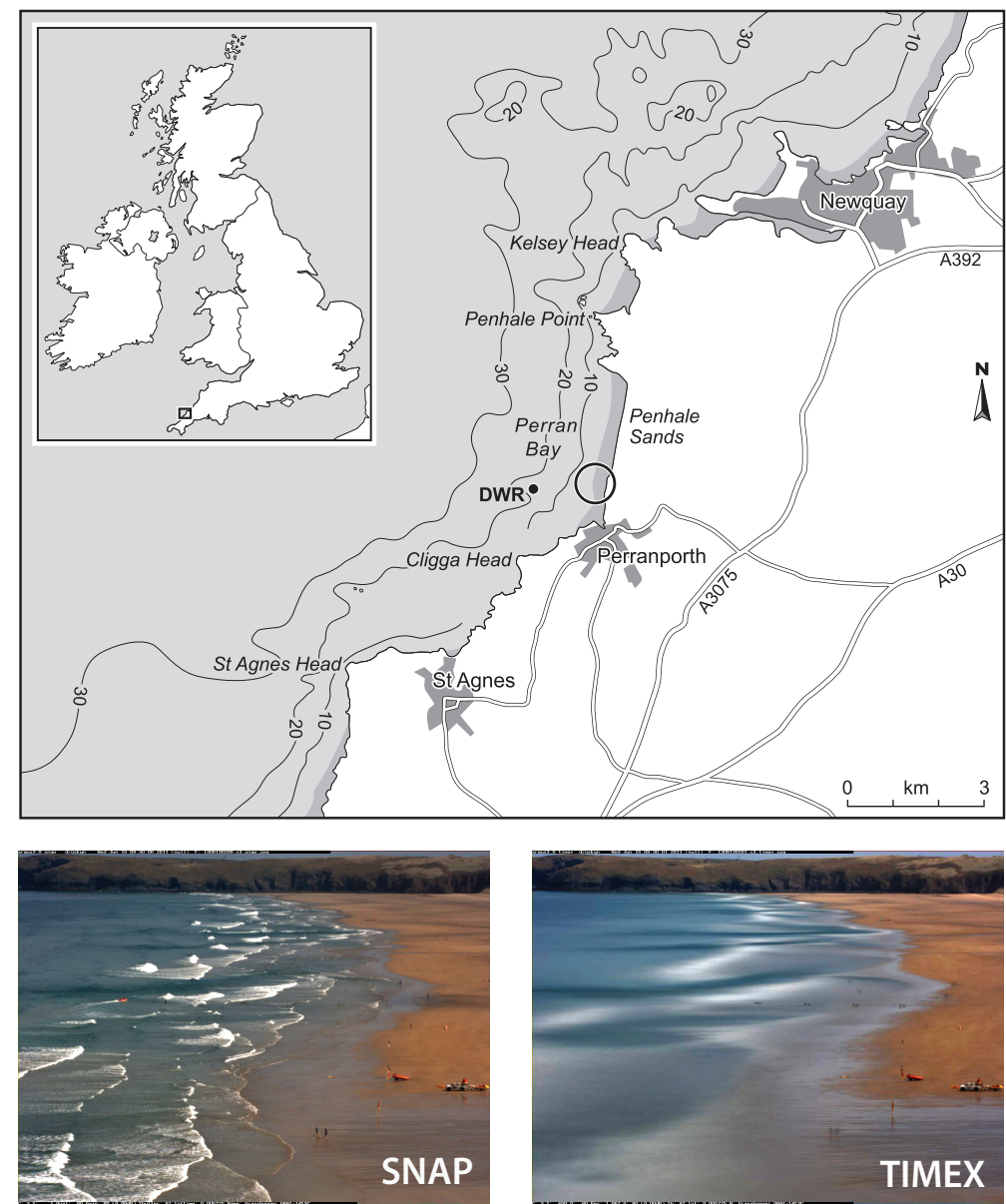

Figure 3: Location map of Perranporth, the site of rip current field experiments during 2011 (upper panel). Study region (circle) and directional wave rider buoy (DWR) are marked. Example Argus video images (snapshot and time-averaged) of rip system during spring 2011 experiment. 

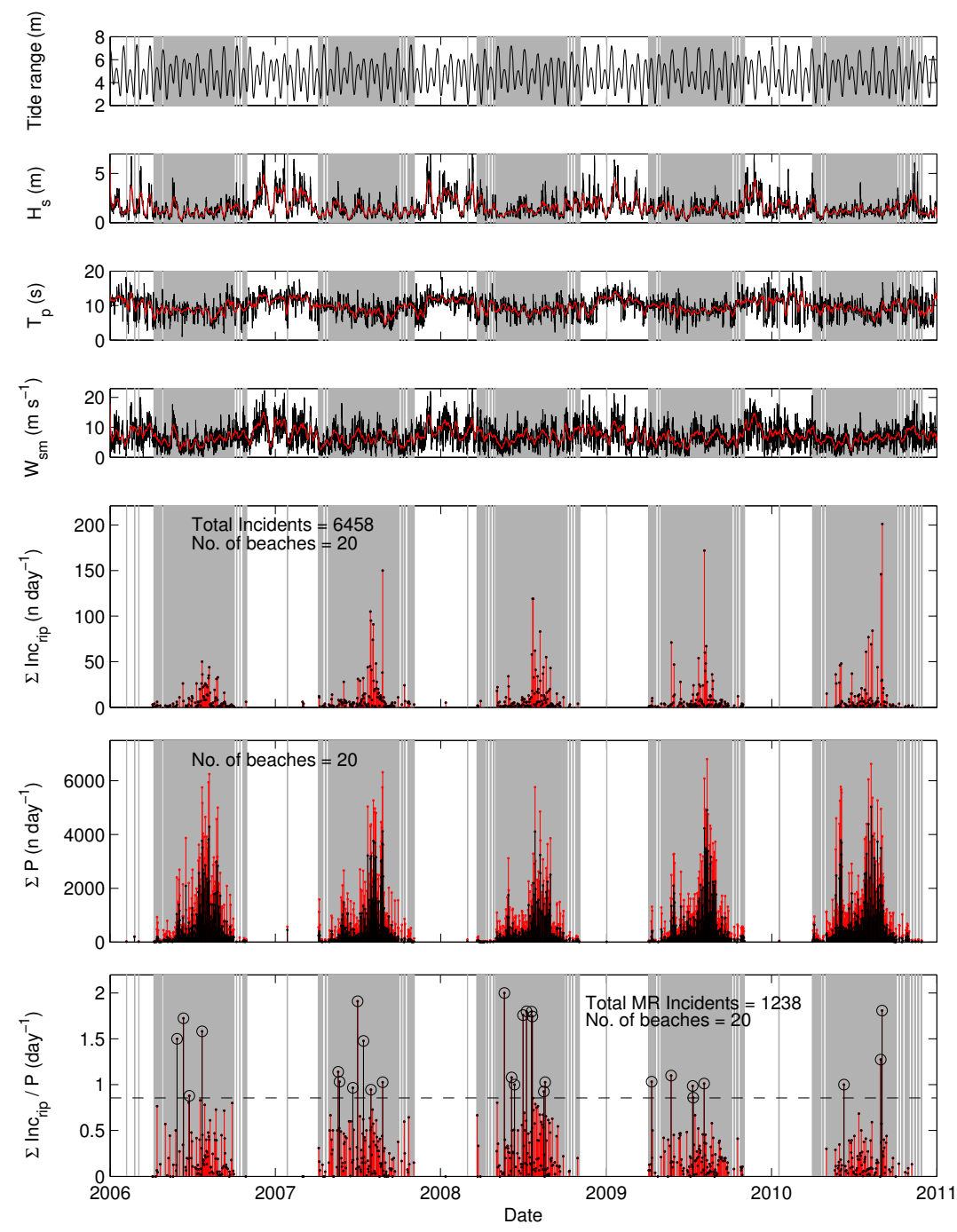

Figure 4: Summary of hydrodynamic conditions from Perranporth and rip incident data throughout all selected sites during 2006-2010. (Top to bottom) Tidal range; significant wave height $H_{s}$; peak $T_{p}$; Mean wind speed $W_{s m}$; total daily rip-related incidents across all beaches $\Sigma I n c_{r i p}$; average number of people in the surf zone $\Sigma P$ across all beaches (black shows swim only, red show swim and surf); and exposure adjusted incident totals $\Sigma\left(I n c_{\text {rip }} / P\right)$ with dashed line indicating 95 th percentile and circles representing days included in the high-risk 'MR' subset. Grey bands indicate days when lifeguards were on patrol. Red lines in upper panels are 12-hour moving averages. 

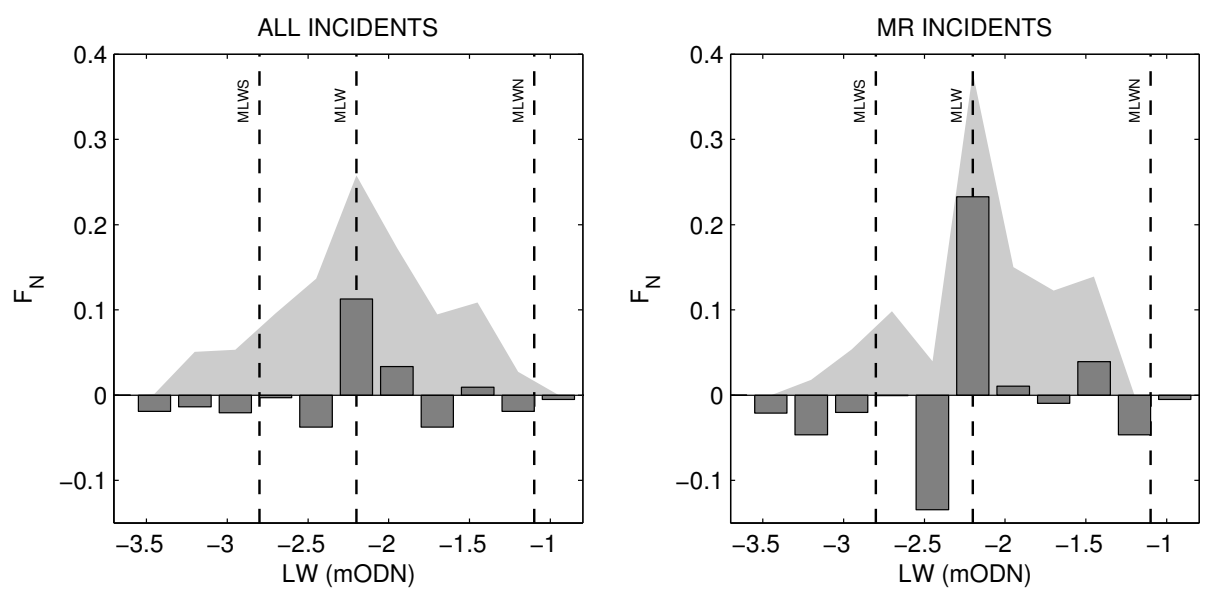

Figure 5: Normalised frequency distributions $F_{N}$ of daily low water elevation $L W$ associated with incidents between 2006 and 2010 (light grey region). Dark grey bars are the difference between the incident-related and the 'average' background distribution, positive values are proportion of the incidentrelated distribution greater than the background. Tidal elevation is relative to Ordnance Datum Newlyn. Dashed lines indicate Mean Low Water Springs (MLWS), Mean Low Water (MLW) and Mean Low Water Neaps (MLWN). Left panel is all incidents and right panel is the $M R$ subset. 

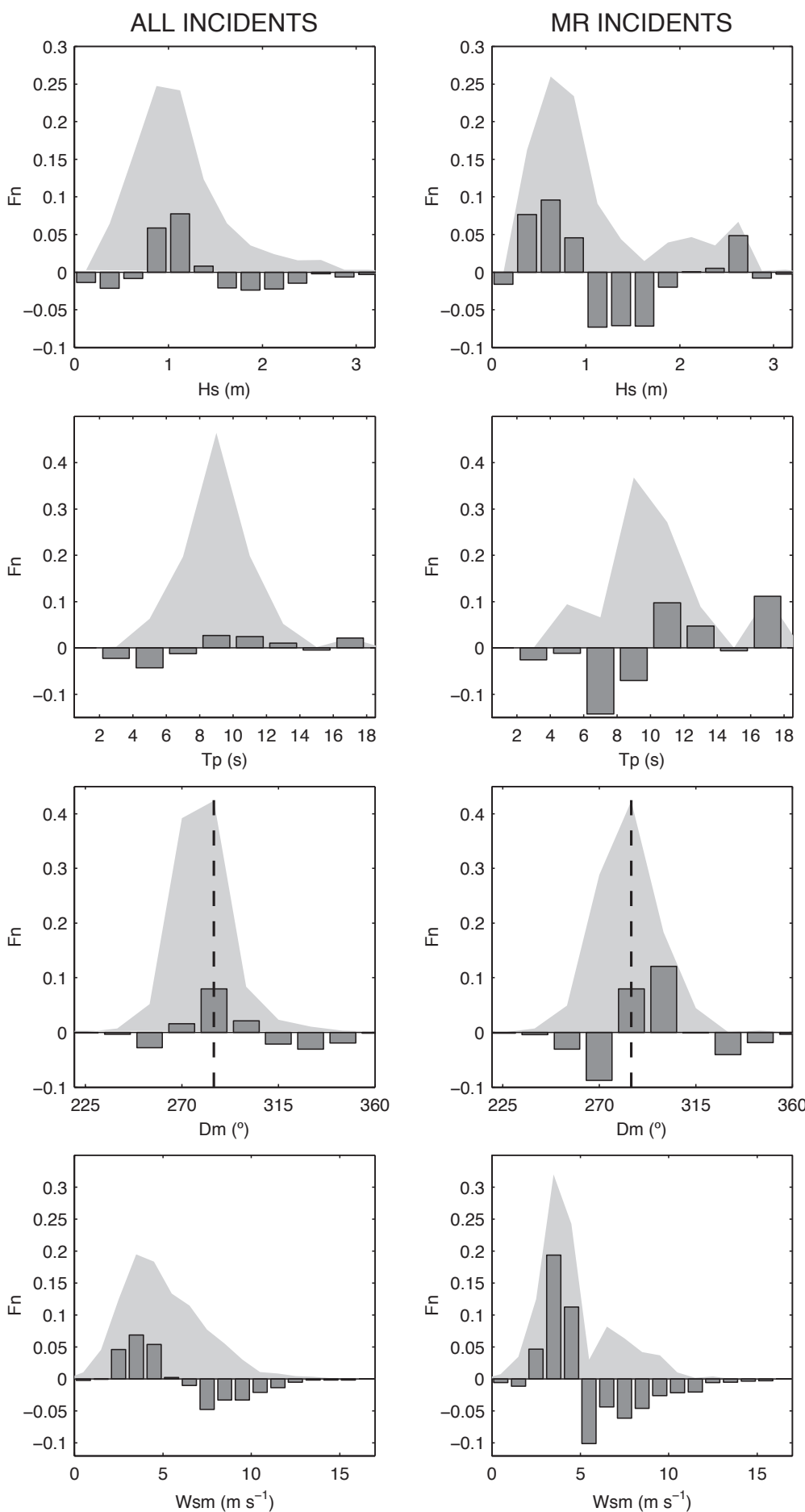

27

Figure 6: Normalised frequency distributions $F_{N}$ of incidents (light grey region) and associated daily wave conditions $H_{s}, T_{p}$ and $D_{m}$ (2006-2010). Dark grey bars are the difference between the distributions. Left panels are all incidents and right panels are the $M R$ subset. Shore normal is 285 degrees at Perranporth. 

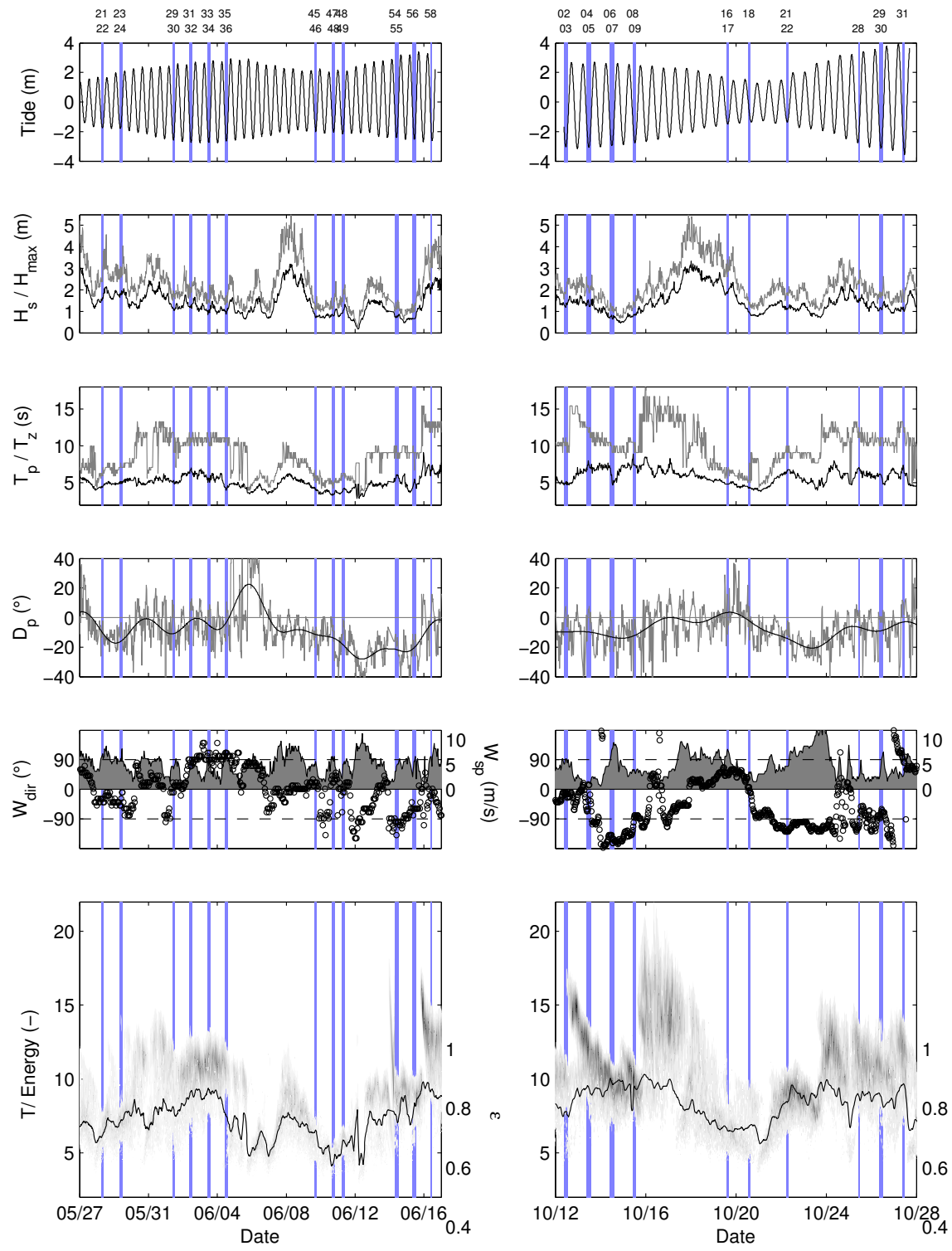

Figure 7: Forcing boundary conditions during both the DRIBS field experiments. From the top, the panels show variation in tidal elevation (in meters relative to Ordnance Datum), significant and maximum wave height $\left(H_{s}\right.$ and $\left.H_{\max }\right)$, peak and mean zero-crossing wave period $\left(T_{p}\right.$ and $\left.T_{z}\right)$, raw and low-pass filtered peak wave direction $\left(D_{p}\right)$ relative to shore normal at Perranporth (angle of origin), mean 10m wind speed and direction $\left(W_{s m}\right.$ and $\left.W_{d i r}\right)$ relative to shore normal with dashed lines indicating threshold between onshore and offshore directed wind, finally the bottom panel shows normalised spectral wave energy against wave period and spectral width $(\epsilon)$. Light blue vertical lines indicate drifter deployments with tide number labels. 


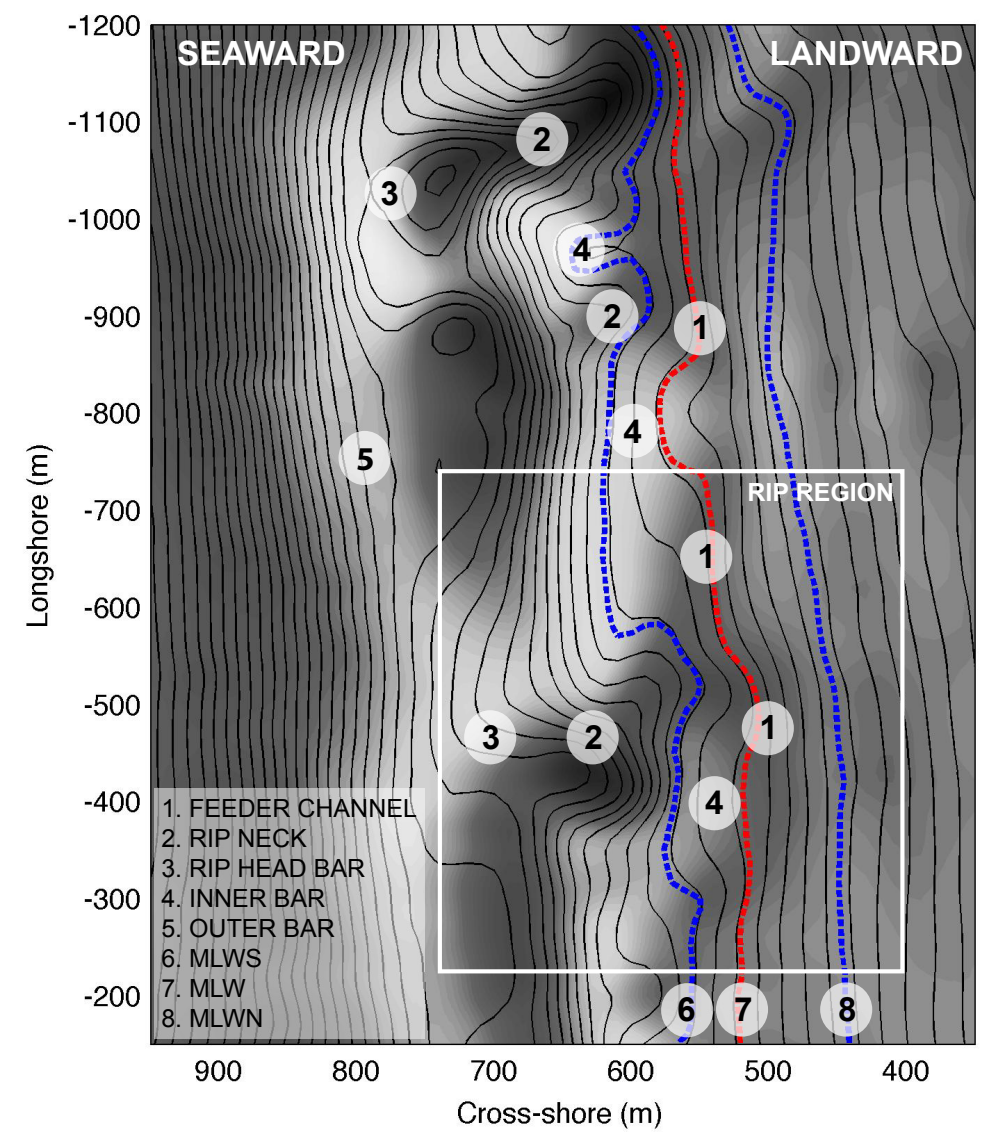

Figure 8: Annotated morphology from Perranporth measured on 6th June 2013. Key morphological features are highlighted. Rip currents studied were located in the region marked with a white box. Elevation contours are $0.25-\mathrm{m}$ separation and shading is residual morphology after removal of linear trend surface. Dashed lines indicate mean low water springs (MLWS), mean low water (MLW) and mean low water neaps (MLWN). This morphology is representative of the whole 2011 dataset. 

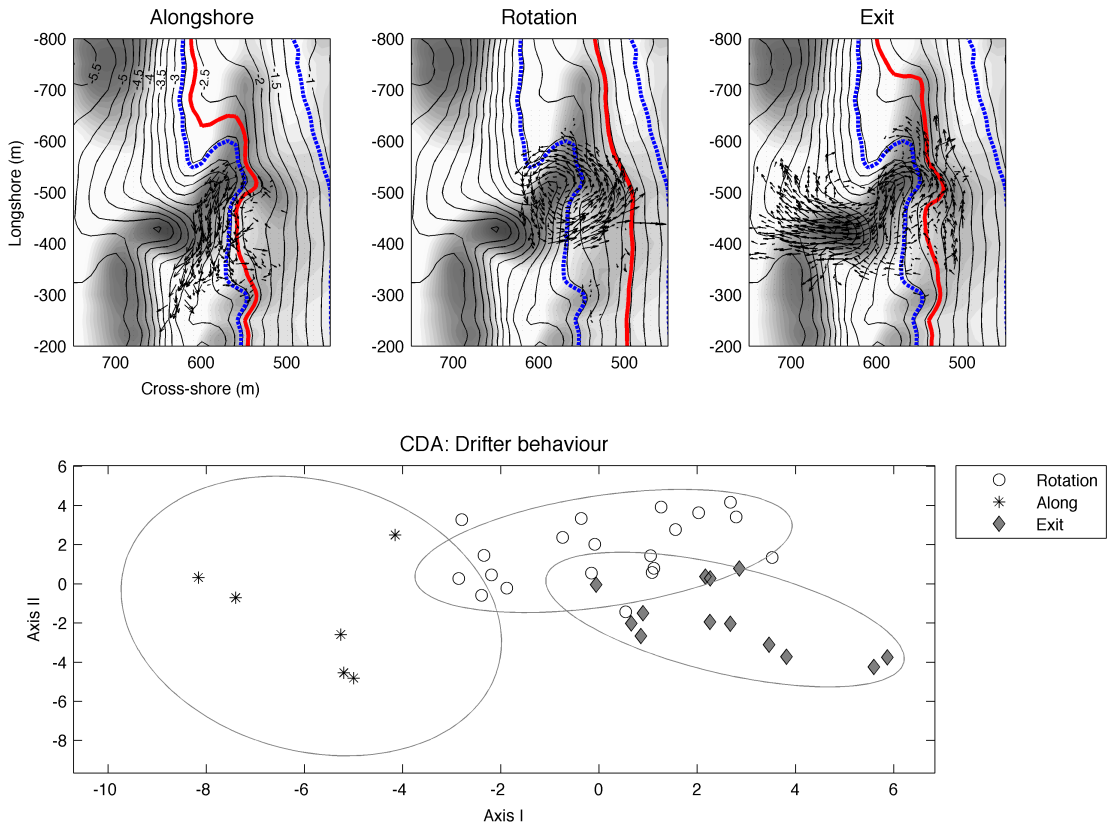

Figure 9: (Upper panels) Example mean drifter circulations from Perranporth field experiments associated with alongshore (left), rotation (middle) and exit (right) dominated deployments. Mean circulation patterns are $10 \mathrm{~m} \mathrm{x} 10 \mathrm{~m}$ binned mean velocities (arrow length is proportion to drifter speed), bathymetric contours $(\Delta 0.25 \mathrm{~m}$ ), daily low water elevations (bold line), MLWN and MLWS (dashed lines) and background is linearly de-trended residual rip channel morphology. (Lower panel) Canonical scores plot produced by discriminant analysis with $80 \%$ confidence ellipses. Axis I and Axis II represents the first and second canonical functions, respectively. 

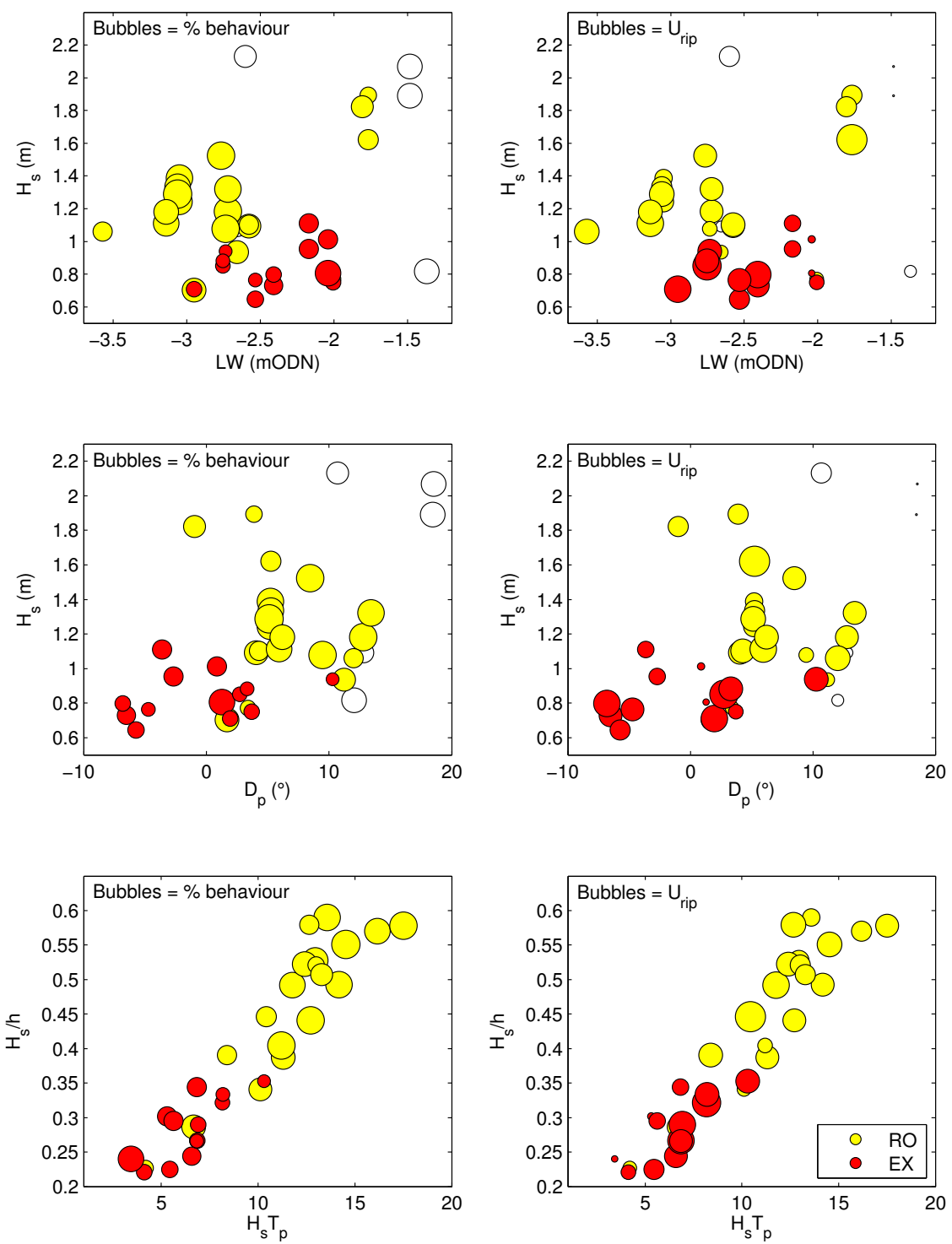

Figure 10: Top panels show summary of distribution of dominant drifter behaviours with $H_{S}$ and $L W$. Bubble size relates to percentage of dominant behaviour (left panels) and maximum $U_{\text {rip }}$ (right panels). Red, yellow and white circles are exit, rotation and alongshore dominated, respectively. Middle panels show distribution with $H_{s}$ and $D_{p}$. Bottom panels show distribution of just exit and rotational behaviours with wave breaking $\left(H_{s} / h\right)$ and wave conditions $\left(H_{s} T_{p}\right)$. 

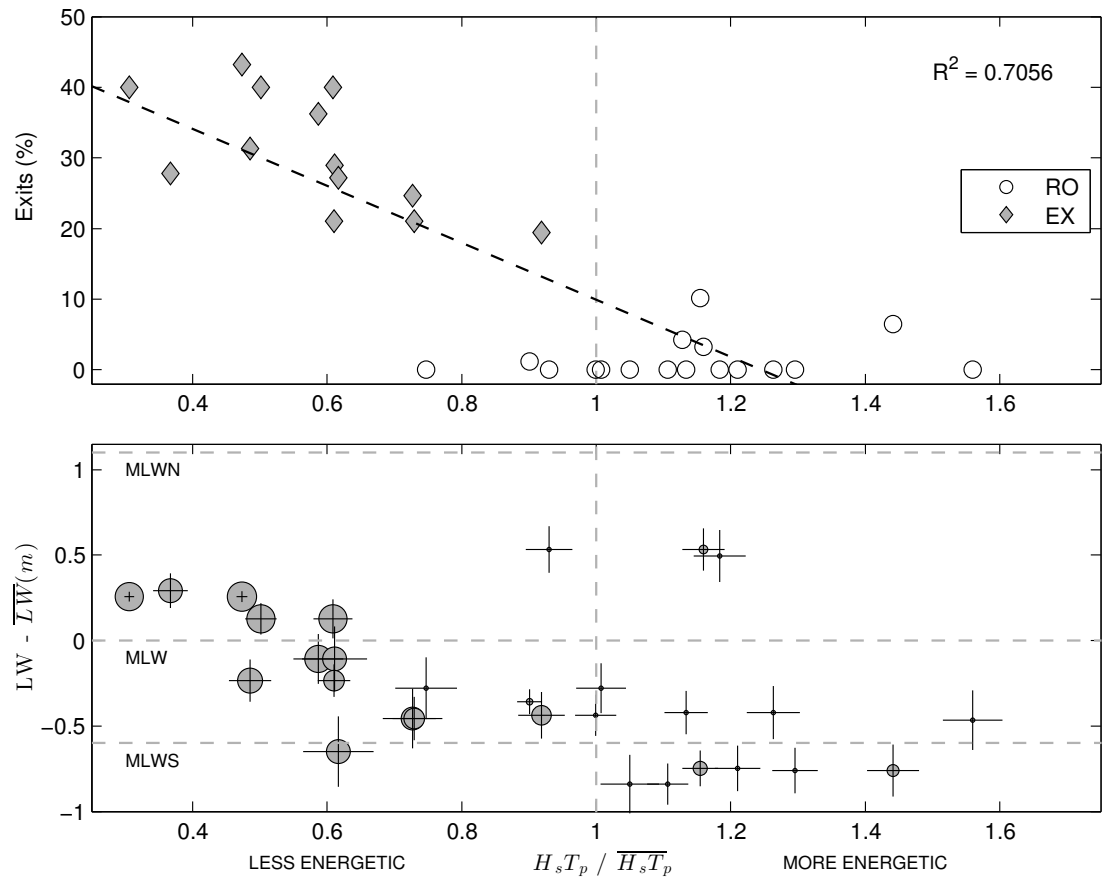

Figure 11: Top panel shows exit percentages of drifter deployments as a function of the wave factor $H_{s} T_{p} / \overline{H_{s} T_{p}}$. Black dashed line is least squares fit with correlation coefficient. Data included are from exit and rotation dominated deployments. Bottom panel shows proportion of exits (bubble size) and values of offshore velocity $U$ (cross size) of drifter deployments as a function of the tide factor $L W-\overline{L W}$ and wave factor $H_{s} T_{p} / \overline{H_{s} T_{p}}$. Horizontal dashed lines indicates mean water levels, vertical dashed line is $\overline{H_{s} T_{p}}$. 

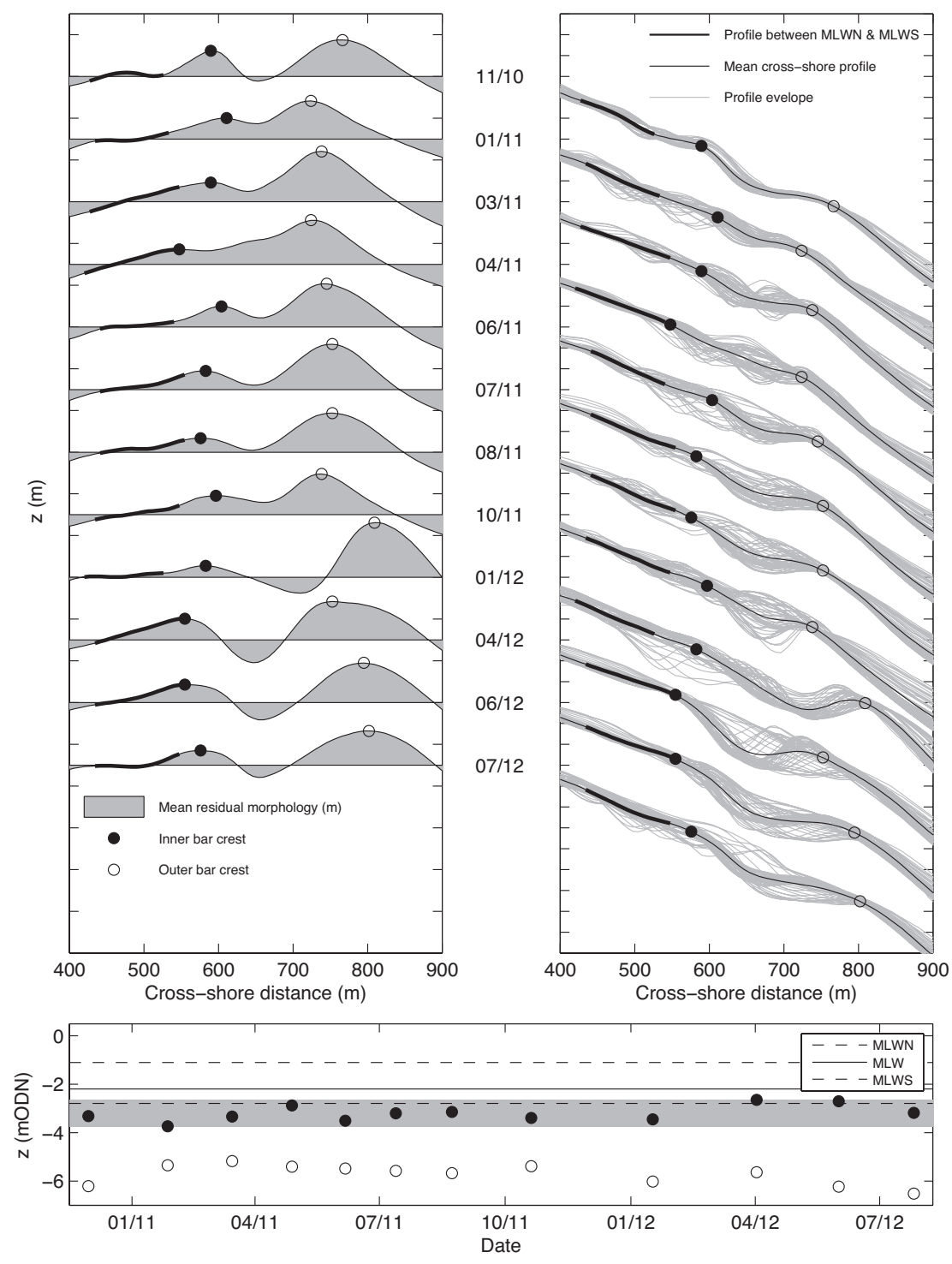

Figure 12: Evolution of bar morphology at Perranporth over the period 2010-2012. (Top left) de-trended cross-shore profiles indicate the location of the inner (black circles) and outer (open circles) bars. (Top right) mean (black line) and alongshore variability in the cross-shore profile $(25 \mathrm{~m})$. Bold lines indicate profiles between MLWN and MLWS. (Bottom) Temporal variation on inner and outer bar elevations associated with the mean cross-shore profile from each measured bathymetry. Shaded region represents observed range of inner bar elevation. Only profile sections of interest between $400-900 \mathrm{~m}$ are shown. 


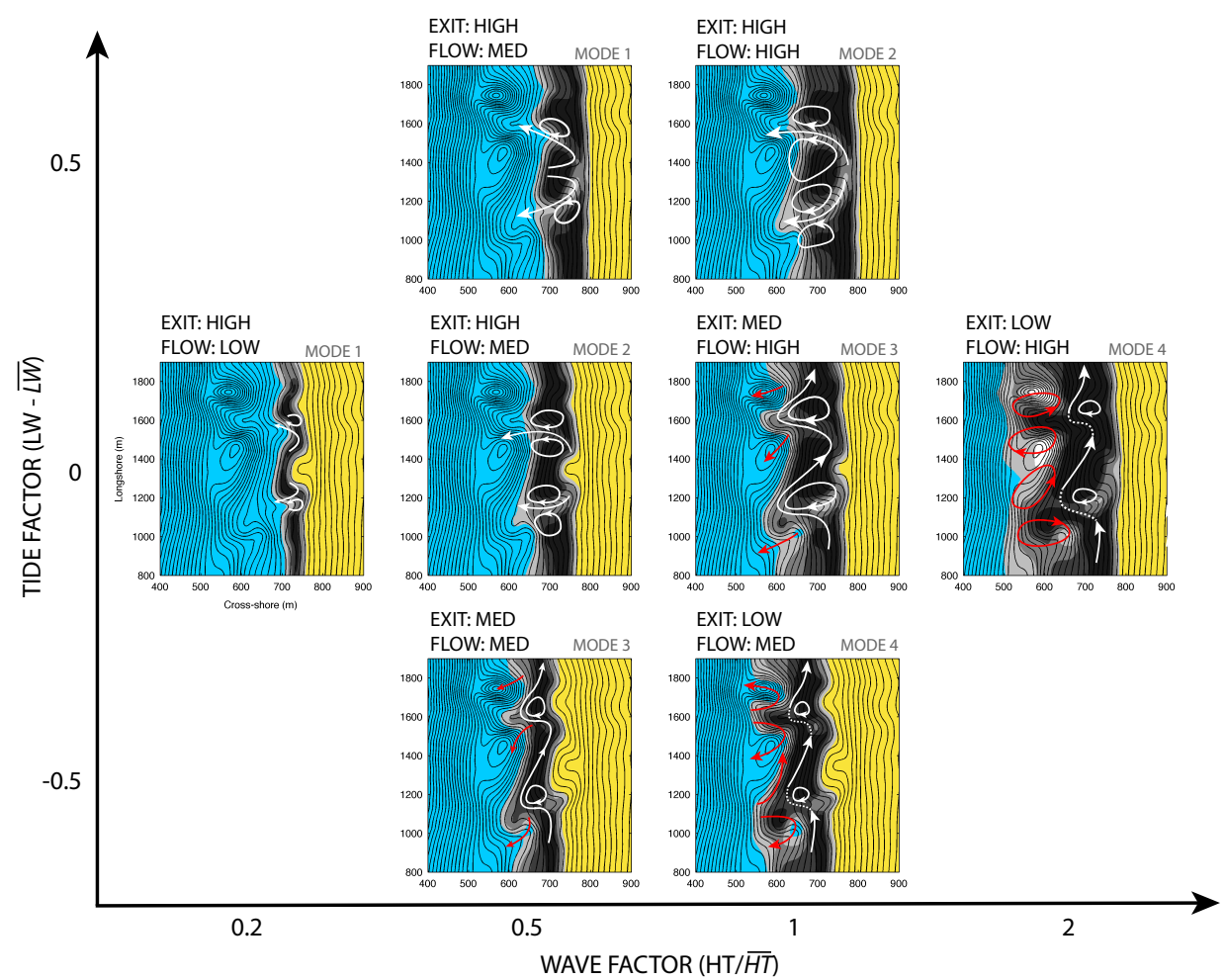

Figure 13: A conceptual overview of the observed rip dynamics throughout the $W_{f}-T_{f}$ parameter space. The schematic diagrams are supported by hydrodynamic model output generated from XBeach using measured bathymetry from June 2011. White arrows are inner surf zone currents, red arrows are outer surf zone currents. Grey shading is the proportion of wave breaking (dark grey is saturated surf zone). For each diagram, levels for surf zone drifter exit potential and flow velocity are given. 

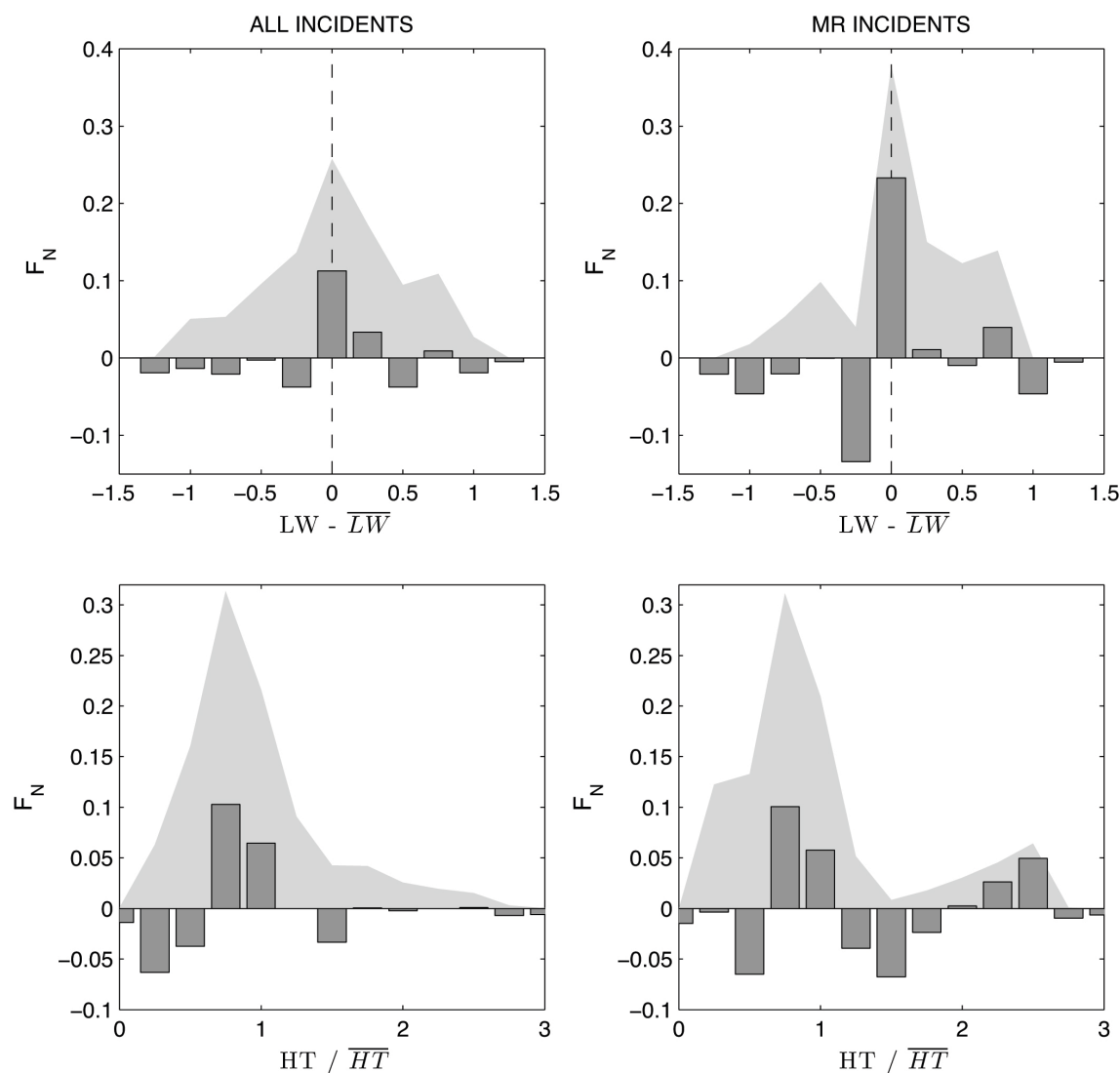

Figure 14: Normalised frequency distributions $F_{N}$ of $W_{f}$ (wave factor $=H_{s} T_{p} / \overline{H_{s} T_{p}}$ ) and $T_{f}$ (tide factor $=L W-\overline{L W}$ ) associated with incidents between 2006 and 2010 (light grey region). Dark grey bars are the difference between the incident-related and the 'average' background frequency distributions, positive values are proportion of the incident-related distribution greater than the background. Dashed lines indicate Mean Low Water (MLW). Left panel is all incidents and right panel is the $M R$ subset. 